\title{
Fotovoltaik Enerji Kaynakı İkili Yapılı Flyback Dönüştürücünün Fuzzy-Tuned PI ve Fractional PID Tipi Denetleyicilerle Gerilim Kararlılığının Karşılaştırılması
}

\author{
Hilmi ZENK ${ }^{1^{*}}$
}

\section{Öz}

Bu çalışmada, fotovoltaik güneş enerjisi üretim sistemi tarafından kontrolü için Fuzzy-tuned PI ve Fractional PID tabanlı kontrolörler ile dual yapılı flyback dönüştürücü tasarımı sunulmuştur. Fotovoltaik güneş enerjisi sisteminde ortam sıcaklığ1 ve güneş radyasyonu seviyeleri değiştiğinden yükler bu değişkenlikten etkilenir. Sistemdeki yüklerin talep ettiği değişken DC gerilim ihtiyacını karşılamak için tasarlanan bu yeni dual flyback dönüştürücü yapısını kullanılarak etkin bir gerilim kontrolü yapıabileceği gösterilmiştir. Dual flyback dönüştürücünün tasarımı ve kontrolü sırasıyla Fuzzy-tuned PI ve Fraksiyonel PID denetleyicisi ile gerçekleştirildi. Sistem verimliliği ve kararlılığı, bu iki farklı kontrolör türünün etkisi altında karşılaştırıldı. Kararlı ve geçici durumlarda sistem performansı çalışmaların teorik tutarlılığını vurgulamak için çalışmalar MATLAB-SIMULINK ortamında gerçekleştirilmiştir.

Anahtar Kelimeler: Fotovoltaik güneş enerjisi, dual flyback dönüştürücü, fuzzy-tuned PI denetleyici, fractional PID denetleyici.

\section{Comparison of Voltage Stability of Photovoltaic Power Source Dual Structure Flyback Converter with Fuzzy-Tuned PI and Fractional PID Type Controllers}

\begin{abstract}
In this study, fuzzy-tuned PI and fractional PID based controllers and a dual structure flyback converter design are presented for the control of a photovoltaic solar energy generation system. Since the ambient temperature and solar radiation levels change in the photovoltaic solar energy system, the loads are affected by this variability. It has been shown that an effective voltage control can be achieved by using this new dual-flyback converter structure designed to meet the variable DC voltage requirement of the loads in the system. The design and control of the dual flyback converter was performed with the fuzzy-tuned PI and fractional PID controller, respectively. System efficiency and stability were compared under the influence of these two different types of controllers. The studies were carried out in MATLABSIMULINK environment to emphasize the theoretical consistency of system performance studies in stable and transient conditions.
\end{abstract}

Keywords: Photovoltaic solar energy, dual flyback converter, fuzzy-tuned PI controller, fractional PID controller.

${ }^{1}$ Giresun Üniversitesi, Mühendislik Fakültesi, Elektrik-Elektronik Mühendisliği Bölümü, Giresun, Türkiye, hilmi.zenk@giresun.edu.tr

${ }^{1}$ https://orcid.org/0000-0002-1653-8580 


\section{Giriş}

Kirliliğe ve iklim değişikliğine neden olan fosil yakıtlar, dünyanın tüm coğrafi bölgelerinde kolay ulaşılamazken, daha rahat ulaşılabilen yenilenebilir enerji kaynaklarından yararlanmak daha verimli bir yoldur (Guner ve Zenk, 2020). Sınırlı ve giderek azalan fosil yakıt rezervleriyle karşı karşıya kalan ülkelerin çoğu artık alternatif enerji kaynakları aramaya başlamaktadır (Şenol ve Zenk, 2020). Ekonomik ve sosyal gelişme ve insan yaşamı için; güvenilir, ucuz ve temiz enerji temini günümüzde en önemli sorun haline gelmiştir (Zenk, 2018a). Geleneksel enerji üretim yöntemlerine alternatif tabiata zarar vermeden elektrik enerjisi üretmenin en etkili yollarından biri de bilindiği gibi güneş enerjisi kullanmaktır. Güneş enerjisinden, elektrik enerjisi üretmek, güneş 1şınlarının yarıiletken malzemelere dikey olarak etkisi prensibine dayanan fotovoltaik olayda tanımlanıyor (Zenk, 2019a). Fotovoltaik olay, güneş 1şığının elektrik enerjisine dönüşümü olarak tanımlanan fiziksel bir fenomendir. Güneş pilleri, güneş ışı̆̆ını doğrudan elektrik enerjisine dönüştürebilen yarı iletkenlerdir. Bu prensiple çalışan güneş pili, üzerine düşen 1şık miktarına bağlı olarak uçlarda bir gerilim üretir. Üretilen gerilim, doğrudan gelen güneş ışığının miktarına bağlı olarak değişir.

Paneller oluşturmak için bir dizi güneş pili birleştirilir ve paneller, PV güç sistemleri oluşturmak için birleştirilir (Zenk, 2018b). Güneş panellerinin çıkışında DC elektrik enerjisinden üretilir. Bu gelen DC gerilim ve gücü, çeşitli güç elektroniği dönüştürücüleri ile DC veya AC yüklere bağlanabilir (Zenk, 2019b).

Güneş pilleri, amorf silikon, bakır indiyum galyum selenid ve kadmiyum tellür gibi birçok malzemeden üretilebilir (Lee ve Ebong, 2017). Güneş panellerinde maliyet ve verimlilik konusunda birçok çalışma bulunmaktadır. Mevcut fotovoltaik panelin verimliliği birçok kez ifade edilmiş ve\% 35'e ulaşmıştır (Praveen ve VijayaRamaraju, 2017). Güneş enerjisi ile büyük miktarda elektrik enerjisi üreten ülkelerde, üretimin önemli şekilde artması, panellerin güç değerlerinin ve verimliliğin artması ile güneş paneli üretim tekniklerinin geliştirilmesi ve daha ekonomik hale gelmesi ile sağlanmıştır.

Fotovoltaik güneş panellerinden üretilen DC tipi elektrik enerjisi, kullanım amacına göre DC veya AC elektrik enerjisine dönüştürülmelidir. Bunun için farklı bir dönüştürücü türü gereklidir. Ancak dönüştürücüler bir kontrol sistemine ihtiyaç duyar. Bu dönüştürücüler, P, PI, PD, PID tipi denetleyiciler (Kiyak ve Gol, 2016;Zenk ve ark., 2019) ile, bulanık mantık tabanlı denetleyicileri (Saygin ve Kerem, 2017), kesirli PID (Rasoanarivo ve ark., 2011), yapay sinir ağları (Soliman ve ark., 2017), vektör denetim yöntemleri (Fathima ve ark., 2017), model öngörücü kontrol (Su ve Sun, 2017) ve genetik algoritmalar (Qian ve ark., 2016) gibi klasik ve gelişmiş denetim yöntemleri kullanılarak denetlenebilir. 


\section{Materyal ve Metot}

Şekil 1'de sırasıyla fuzzy-tuned PI denetleyici ve fractional PID'ye bağlı dual yapılı Flyback dönüştürücü ve enerji kaynağı olarak güneş paneli bağlı sistemin genel şeması verilmiştir. Güneş panelleri 3 paralel kol ve Her dalda 3 panel. Bu panellerden gelen DC gerilim, Dual-Flyback dönüştürücüye bağlanır. Çıkış gerilimini istenen referans aralığında kontrol etmek için alınan örnekler kontrol ünitesine girer. Kontrolör çıkışındaki kontrol sinyalleri PWM sinyali üretecine bağlanır ve anahtar sinyalleri üretilir. Bu sinyaller Flyback dönüştürücünün anahtarını çalıştırarak referans değerde gerilim üretilmesini sağlar.

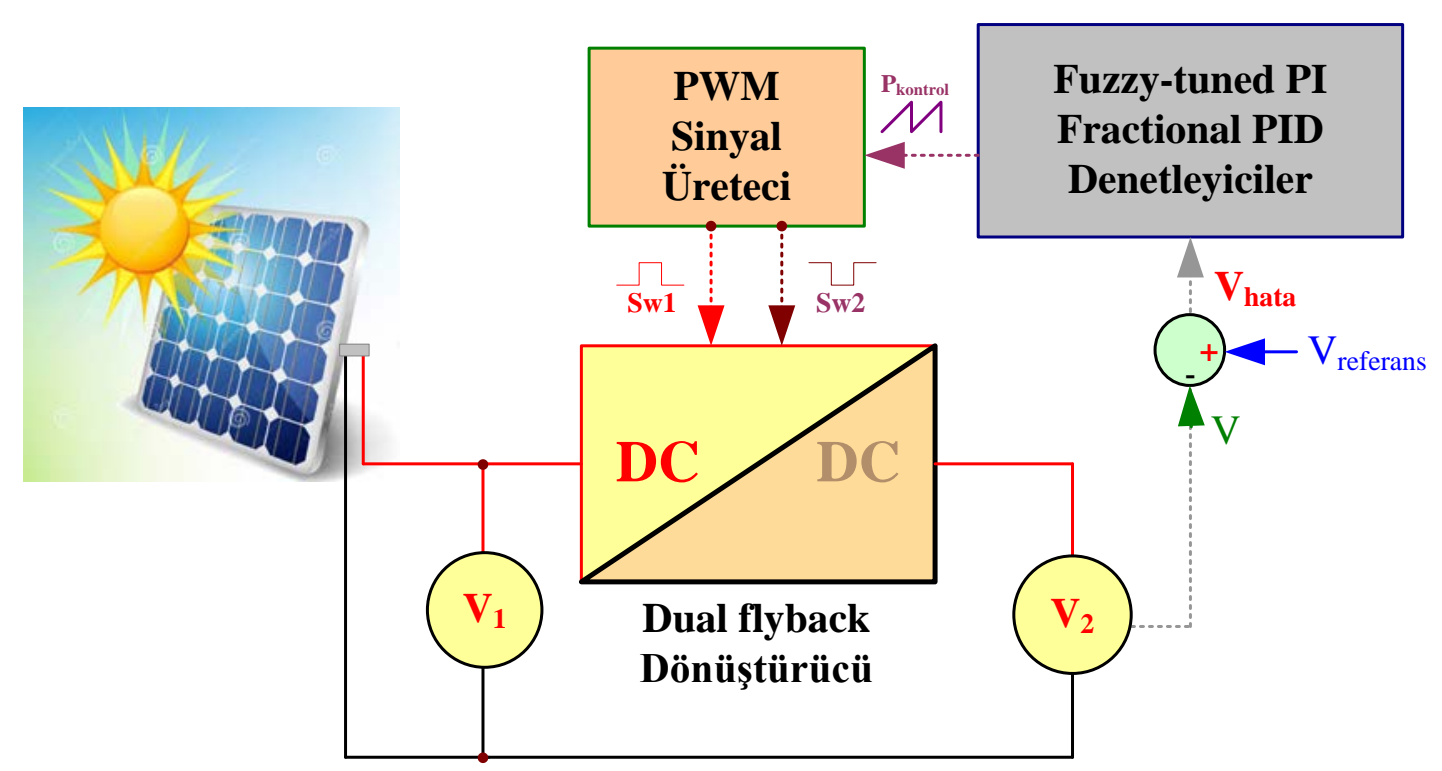

Şekil 1. Sistemin genel blok diyagramı.

\subsection{Dual Flyback Dönüştürücünün Çalışması}

Elektriksel güç dönüşümü ihtiyacı gereken durumlarda, güç elektroniğgi dönüştürücüleri kullanılır. Yalıtım ve düşük güç gerektiren uygulamalarda daha çok forward ve flyback dönüştürücü türleri tercih edilmektedir (Finney ve ark., 1996). Flyback tabanlı trafo devre tasarımları kolay kontrolü ve az sayıda eleman olması nedeniyle tercih edilmektedir. Ancak, Flyback tipi dönüştürücülerde kullanılan transformatörünün kaçak endüktansı önemli bir sorun olarak karşımıza çıkar. Bu kaçak endüktans, dönüştürücüdeki kontrol anahtarında ciddi gerilim artışına ve yüksek güç kayıpları gibi olumsuz etkilere neden olur. Bu sorunları iyileştirmek için bazı teknikler mevcuttur. Bu tekniklerden birisi aktif anahtarlardaki (Chen ve ark., 2000) voltaj artışlarını sınırlamak için bir fren direnci (RCD) kullanılabilir. Bu yöntemle birlikte, trafonun kaçak endüktansında depolanan enerji, RCD direnci üzerinde dağıtılır. 
Başka bir yöntemde transformatörlerin, kaçak enerjisini geri dönüştürmek için iki anahtarlı dual tipli flyback dönüştürücü yapısı kullanılabilir (Kim ve Jung, 2009). Ancak bu devre topolojisinde iki aktif anahtara ihtiyaç vardır (Murthy-Bellur ve Kazimierczuk, 2011). Aktif anahtarlardaki gerilim artışını ortadan kaldırmak için aktif bir clamp devresi uygulanabilir. Ek olarak, bu dönüştürücü, aktif anahtar için sıfır voltaj anahtarlaması da sağlayabilir. Ancak, bu dönüştürücüde yüksek güç uygulamaları için iki transformatör kullanır Spiazzi ve ark., 2011). Önerilen dönüştürücünün devre konfigürasyonu Şekil 2'de gösterilmektedir. Önerilen dönüştürücü, bir anahtar $S$, iki $T_{1}$ ve $T_{2}$ transformatör, üç diyot ve üç kapasitörden oluşur (Zenk, 2018c). $\mathrm{T}_{1}$ ve $\mathrm{T}_{2}$ transformatörlerindeki sargılar aynı rölatif dönüş yönlerine sahiptir, $N_{1 p}=N_{2 p}$ ve $N_{1 s}=N_{2 s}$ ve dönüş oranları $a=N_{1 s} / N_{1 p}$ $=\mathrm{N}_{2 \mathrm{~s}} / \mathrm{N}_{2 \mathrm{p}}$. $\mathrm{T}_{1}$ ve $\mathrm{T}_{2}$ transformatörlerinin kaçak enerjileri, kapalı periyot S'de $\mathrm{D}_{1}$ diyot aracılığıyla $C_{1}$ ve $C_{2}$ kapasitörlerine geri dönüştürülebilir. $\mathrm{Bu}$ nedenle güç kayıpları azaltılabilir. Önerilen dönüştürücünün devre analizini basitleştirmek için, tüm bileşenlerin ideal olduğu varsayılır. Bu nedenle devre elemanlarının kayıpları hesaba katılmaz. Ayrıca devredeki kapasitörler yeterince büyüktür. Bu kapasitörlerdeki voltajlar, her anahtarlama döneminde sabit kabul edilir.

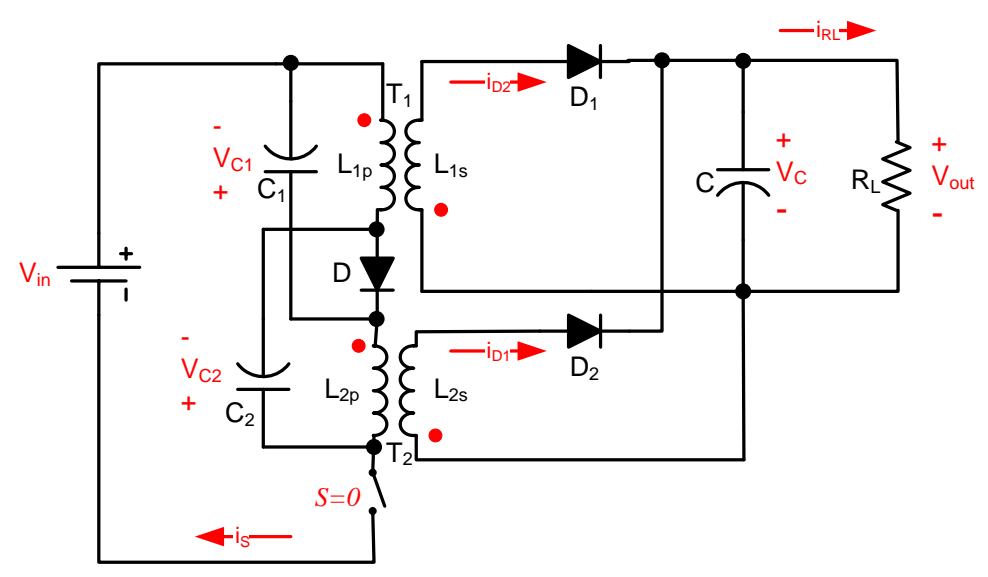

Şekil 2. Dual flyback konvertör basit devre modeli.

Dual flyback dönüştürücünün eşdeğer bir devresi Şekil 3'te gösterilmektedir. S anahtarı, darbe genişliği modülasyon stratejisi kullanılarak kontrol edilir. $T_{1}$ ve $T_{2}$ transformatörlerinin karş1lıklı manyetik endüktans1 $L_{m 1 p}$ ve $L_{m 2 p}$, kaçak indüktansları $L_{k 1 p}$ ve $L_{k 2 p}$ ideal transformatörler olarak modellenmiştir. $T_{1}$ ve $T_{2}$ transformatörlerinin sargıları eşdeğer olduğundan, mıknatıslanma endüktans denklemi (1) ve kaçak indüktanslar denklem (2) 'de verildiği gibi eşit kabul edilir. $\mathrm{T}_{1}$ ve $\mathrm{T}_{2}$ transformatörlerinin kuplaj katsayısı k denklem (3) 'te verilmiştir. 


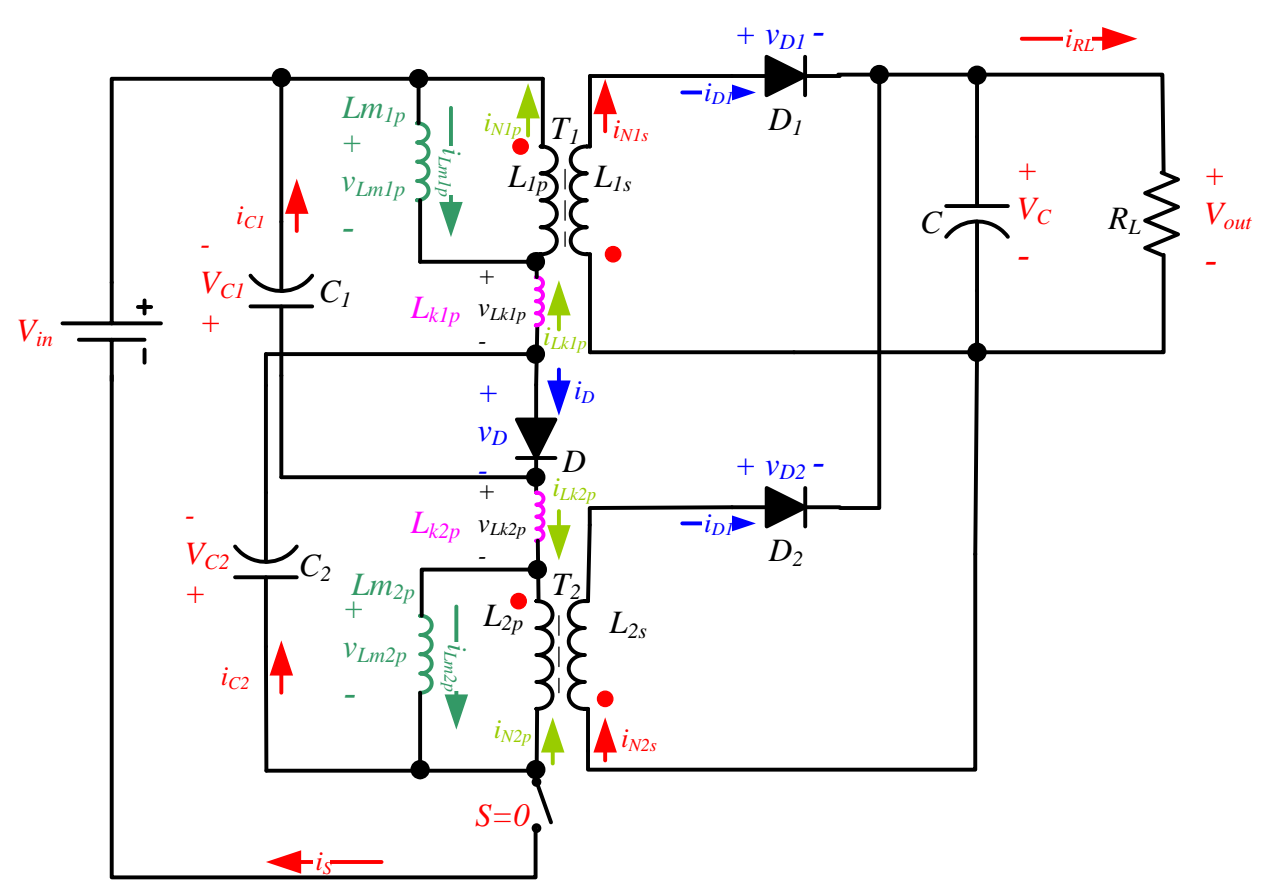

Şekil 3. Dual flyback konvertör eşdeğer devresi.

$$
\begin{aligned}
& L_{m}=L_{m 1 p}=L_{m 2 p} \\
& L_{k}=L_{k 1 p}=L_{k 2 p} \\
& k=\frac{L_{m 1 p}}{L_{m}+L_{k}}
\end{aligned}
$$

Sürekli çalışma modunda (CCM) bir anahtarlama periyodu sırasında önerilen dual flyback dönüştürücü devresindeki bazı devre elemanlarının akım-gerilim ifadeleri denklemler (4) - (8)'de verilmiş, akım-gerilim (i-v) dalga formları Şekil 4'te gösterilmiştir. 


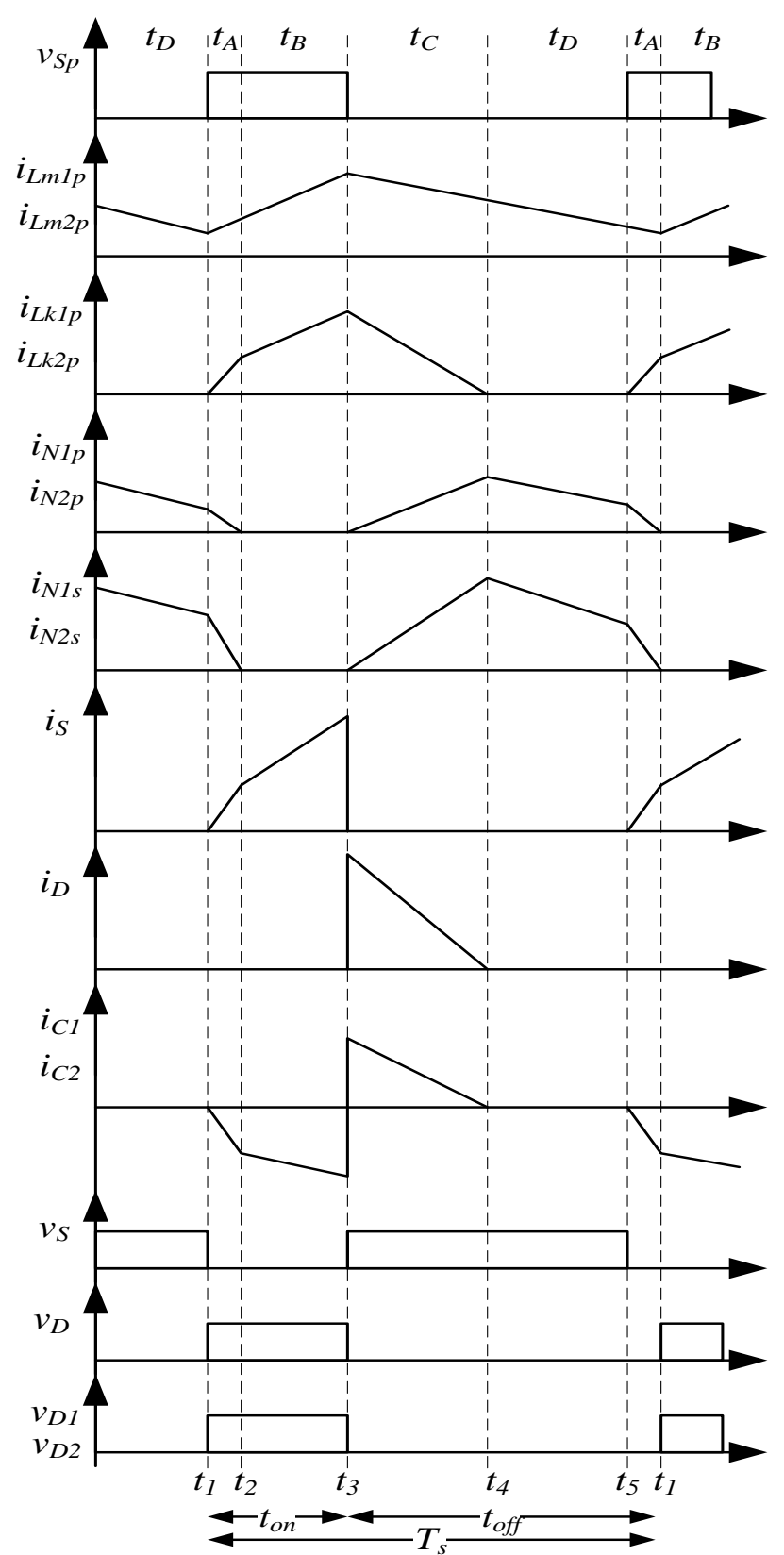

Şekil 4. Dual flyback dönüştürücünün akım ve gerilim dalga formları.

$$
\begin{aligned}
& v_{L m}=v_{L m 1 p}=v_{L m 2 p} \\
& v_{L k}=v_{L k 1 p}=v_{L k 2 p} \\
& i_{L m}=i_{L m 1 p}=i_{L m 2 p} \\
& i_{L k}=i_{L k 1 p}=i_{L k 2 p} \\
& V_{C}=V_{c 1}=V_{c 2}
\end{aligned}
$$


Önerilen dual flyback dönüştürücünün sürekli akım çalışma modunu açıklamak için, devredeki anahtarın çalışma periyodunun belirli zaman aralıklarında farklı devre analizlerinin incelenmesi gerekir.

\subsubsection{Dual Flyback Dönüştürücünün A Çalışma Modu $\left(t_{a}=t_{2}-t_{1}\right)$}

S aktif anahtarının açık olduğu durumdaki devre akım yönleri Şekil 5'te gösterilmektedir. Transformatörlerin $L_{m 1 p}$ ve $L_{m 2 p}$ mıknatıslanma endüktanslarında depolanan enerjiler, ideal kondansatörler ve $\mathrm{D}_{2}$ ve $\mathrm{D}_{3}$ diyotları aracılığıyla $\mathrm{C}_{\mathrm{o}}$ çıkış kondansatörüne ve $\mathrm{R}$ yüküne aktarılır. Giriş gerilim kaynağı $V_{\text {in }}$, kapasitör $C_{1}$ ve mıknatıslanma endüktansı $L_{m 2 p}$, enerjilerini aktif anahtar $S$

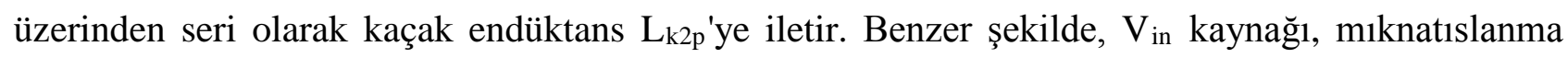
endüktansı $\mathrm{L}_{\mathrm{m} 1 \mathrm{p}}$ ve kapasitör $\mathrm{C}_{2}$, enerjileri seri olarak $\mathrm{S}$ aktif anahtarı üzerinden kaçak endüktans $L_{k 1 p}$ 'ye aktarır. Bu nedenle, Şekil 4'te gösterildiği gibi mıknatıslanma endüktans akımları $i_{\text {Lm1p }}$ ve $i_{\text {Lm2p }}$ azaltılır ve kaçak endüktans akımları $i_{\text {Lk1p }}$ ve $i_{L k 2 p}$ artar. Bu mod, $i_{L m 1 p}$ ve $i_{L m 2 p}$ mıknatıslanma endüktans akımları, $i_{\text {Lk1p }}$ ve $i_{\text {Lk2p }}$ kaçak endüktans akımlarına eşit olduğunda $t_{2}$ 'de sona erer.

Miknatıslanma endüktansı $L_{m 1 p}$ ile $L_{m 2 p}$ arasındaki gerilimler ve $L_{k 1 p}$ ve $L_{k 2 p}$ kaçak endüktansları denklem (9) - (12) ile hesaplanabilir.

$$
\begin{aligned}
& v_{L m}^{A}=-\frac{V_{0}}{a} \\
& v_{L k}^{A}=V_{i n}+V_{c}+\frac{V_{0}}{a} \\
& i_{L m}^{A}(t)=-\frac{V_{\text {in }}}{a L_{m}}\left(t-t_{1}\right)+i_{L m}\left(t_{1}\right) \\
& i_{L k}^{A}(t)=\frac{1}{L_{k}}\left(V_{\text {in }}+V_{c}+\frac{V_{0}}{a}\right)\left(t-t_{1}\right)
\end{aligned}
$$




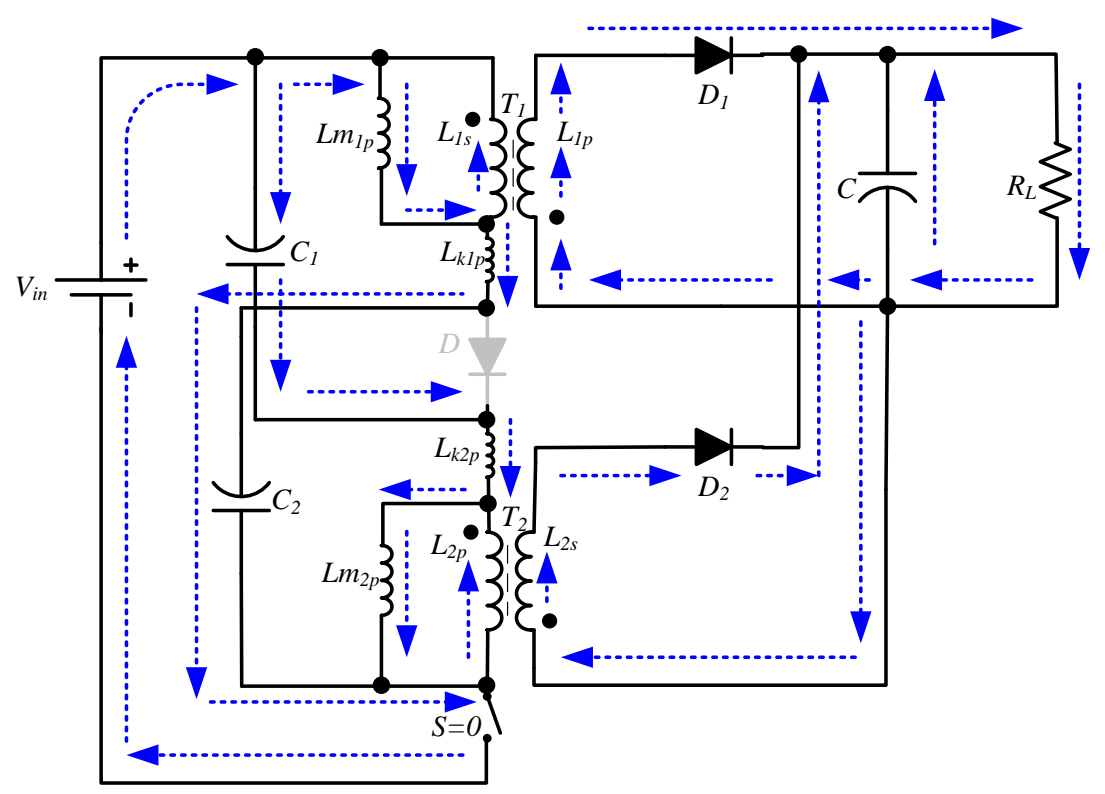

Şekil 5. Dual flyback konvertörün A modunda çalışırken akım yönleri.

\subsubsection{Dual Flyback Dönüştürücünün B Çalışma Modu $\left(t_{b}=t_{3}-t_{2}\right)$}

Flyback dönüştürücünün 2. çalışma modunda, devredeki S anahtarı açık pozisyonda kalır. Mevcut yönler Şekil 6'da kesikli oklarla gösterilmiştir. $V_{\text {in }}$ kaynağı ve $C_{1}$ kondansatörü, $S$ aktif anahtarı aracılığıyla manyetizasyon endüktansı $L_{m 2 p}$ ve kaçak endüktansı $L_{k 2 p}$ için enerjilerini iletmek üzere seri olarak bağlanmıştır. Öte yandan, $V_{\text {in }}$ kaynağ 1 ve $C_{2}$ kondansatörü, mıknatıslanma endüktans $\mathrm{L}_{\mathrm{m} 1 \mathrm{p}}$ ve kaçak indüktans $\mathrm{L}_{\mathrm{k} 1 \mathrm{p}}$ enerjilerini aktif anahtar $\mathrm{S}$ üzerinden aktarmak için seri olarak bağlanır. Çıkış kondansatörü C'de depolanan enerji, R yükünde boşaltılır. Bu nedenle, B modu sırasında mıknatıslanma endüktans akımları $i_{L m 1 p}$ ve $i_{L m 2 p}$ ve kaçak endüktans akımları $i_{L k 1 p}$ ve $i_{L k 2 p}$ artar. Mod B, t 3 anında S anahtarı kapalı konuma geçtiğinde sona erer. Bu süre zarfında (13) - (18) denklemleri elde edilir.

$$
\begin{aligned}
& v_{L m}^{B}+v_{L k}^{B}=V_{i n}+V_{c} \\
& i_{L k}^{B}=i_{L m}^{B} \\
& v_{L k}^{B}=L_{k} \frac{d i_{L k}^{B}}{d t}=\frac{1-k}{k} L_{m} \frac{d i_{L m}^{B}}{d t} \\
& v_{L k}^{B}=\frac{1-k}{k} v_{L m}^{B} \\
& v_{L m}^{B}=k\left(V_{i n}+V_{c}\right)
\end{aligned}
$$




$$
i_{L m}^{B}(t)=\frac{\left(V_{i n}+V_{c}\right)}{L_{m}}\left(t-t_{2}\right)+i_{L m}\left(t_{2}\right)
$$

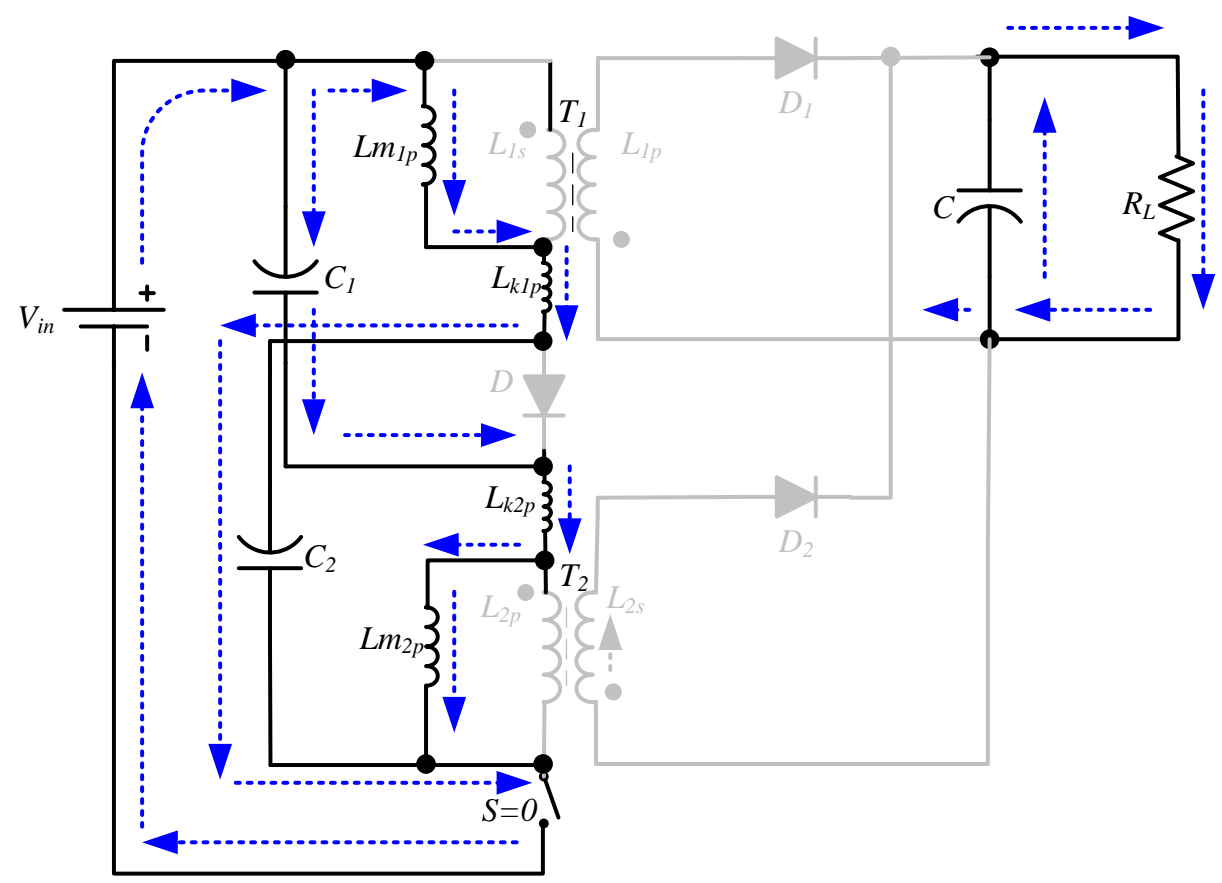

Şekil 6. Dual flyback konvertörün B modunda çalışırken akım yönleri.

\subsubsection{Dual Flyback Dönüştürücünün C Çalışma Modu $\left(t_{c}=t_{4}-t_{3}\right)$}

S anahtarı, çalışma modundan C kapalı konumdadır. Devre akım yönleri Şekil 7'de gösterilmiştir. Mıknatıslanma endüktansı $L_{m 2 p}$ ve kaçak endüktans $L_{k 2 p}$, enerjilerini $C_{2}$ kondansatörü ile seri olarak D diyotuna iletir. Benzer şekilde, devrenin diğer kısmında, Lm1p mıknatıslanma endüktansında ve $\mathrm{L}_{\mathrm{k} 1 \mathrm{p}}$ kaçak endüktansında depolanan enerji, seri bağlı bir $\mathrm{D}$ diyot kullanılarak $\mathrm{C}_{1}$ kapasitörüne aktarılır. Böylece kaçak enerjiler geri kazanılır ve kayıp azaltılır. Mıknatıslanma endüktanslarında $L_{m 1 p}$ ve $L_{m 2 p}$ depolanan enerjiler $T_{1}-T_{2}$ transformatörleri, $D_{1}-D_{2}$ diyotlar1 aracılığıyla R yüküne yatırılır. C çıkış kapasitörünün çıkışı da R yüküne boşaltılır. Bu nedenle, Şekil 4'te gösterildiği gibi mıknatıslanma indüktans akımları $i_{\text {Lm1p }}$ ve $i_{L m 2 p}$ ve kaçak indüktans akımları $i_{L k 1 p}$ ve $i_{L k 2 p}$ azalır. C çalışma modunun sonunda yani t4'te; $i_{\text {Lk1p }}$ ve $i_{\text {Lk2p }}$ kaçak endüktans ak1m değerleri sıfırdır. C modu sırasında $\mathrm{L}_{\mathrm{m} 1 \mathrm{p}}$ - $\mathrm{L}_{\mathrm{m} 2 \mathrm{p}}$ mıknatıslanma endüktansları ve $\mathrm{L}_{\mathrm{k} 1 \mathrm{p}}-\mathrm{L}_{\mathrm{k} 2 \mathrm{p}}$ kaçak endüktans akımı ve gerilim ifadeleri (19) ve (22) nolu denklemlerde verilmiştir.

$$
\begin{aligned}
& v_{L m}^{C}=-\frac{V_{0}}{a} \\
& v_{L k}^{C}=\frac{V_{0}}{a}-V_{C}
\end{aligned}
$$




$$
\begin{aligned}
& i_{L m}^{C}(t)=-\frac{V_{0}}{a L_{m}}\left(t-t_{3}\right)+i_{L m}^{B}\left(t_{3}\right) \\
& i_{L k}^{C}(t)=\frac{1}{L_{k}}\left(\frac{V_{0}}{a}-V_{c}\right)\left(t-t_{3}\right)+i_{L k}^{B}\left(t_{3}\right)
\end{aligned}
$$

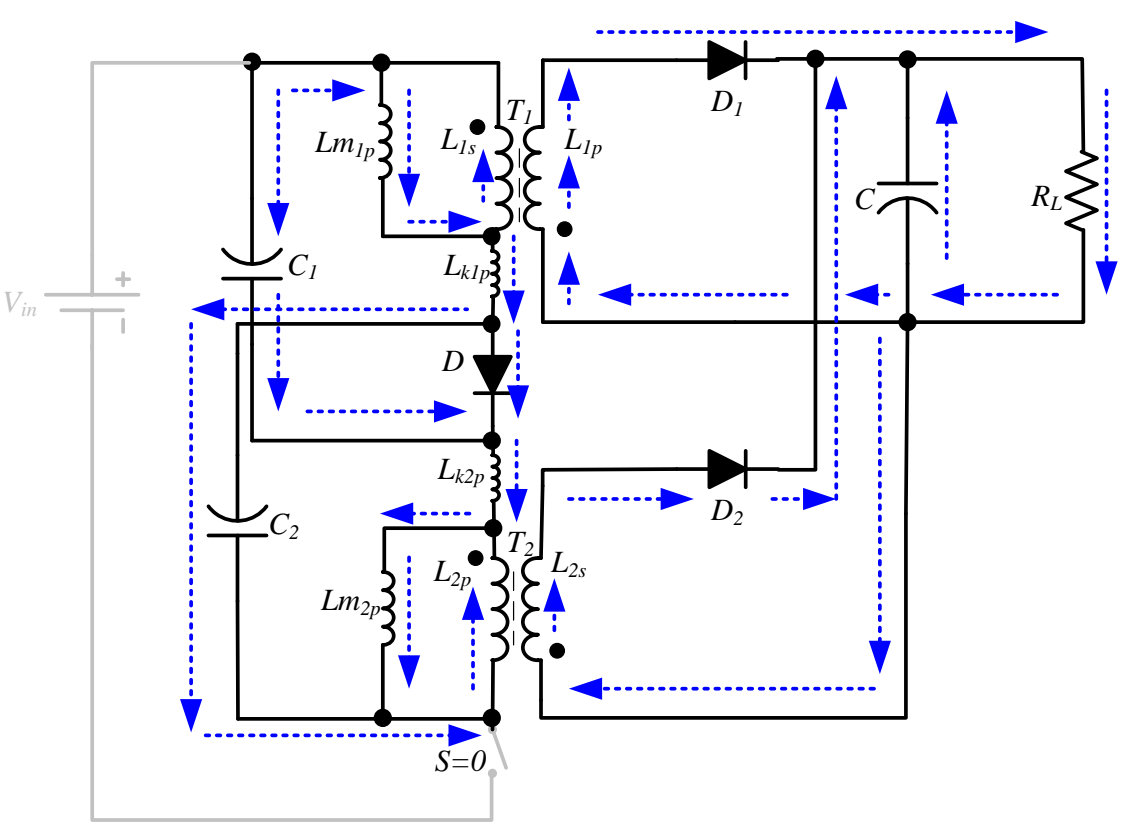

Şekil 7. Dual flyback konvertörün C modunda çalışırken akım yönleri.

\subsubsection{Dual Flyback Dönüştürücünün D Çalışma Modu $\left(t_{d}=t_{5}-t_{4}\right)$}

D çalışma modunda, S anahtarı kapalı konumunda kalır. Devredeki enerji akış yönü Şekil 8'de detaylı olarak gösterilmiştir. Mıknatıslanma endüktansları $\mathrm{L}_{\mathrm{m} 1 \mathrm{p}}$ ve $\mathrm{L}_{\mathrm{m} 2 \mathrm{p}}$ de depolanan enerjiler, ideal kapasitörler ve $\mathrm{D}_{1}-\mathrm{D}_{2}$ diyotlar aracılığıyla $\mathrm{C}$ çıkış kondansatörüne ve $\mathrm{R}$ yüküne aktarılır. Böylece, mıknatıslanma endüktans akımları $i_{\text {Lm1p }}$ ve $i_{\text {Lm2p }}$, Şekil 4'te gösterildiği gibi azaltılır. D modunda, S anahtarı yalnızca t 5 açık konuma getirildiğinde açılır. Öte yandan, $t_{5}$ zamanı bir sonraki anahtarlama döneminin başlangıç noktasıdır. Mıknatıslanmış endüktanslar $\mathrm{L}_{\mathrm{m} 1 \mathrm{p}}$ ve $\mathrm{L}_{\mathrm{m} 2 \mathrm{p}}$, D modu, voltaj denklemi (23) ve akım denklemi (24) boyunca verilmektedir.

$$
\begin{aligned}
& v_{L m}^{D}=-\frac{V_{0}}{a} \\
& i_{L m}^{D}(t)=-\frac{V_{0}}{a L_{m}}\left(t-t_{4}\right)+i_{L m}^{C}\left(t_{4}\right)
\end{aligned}
$$




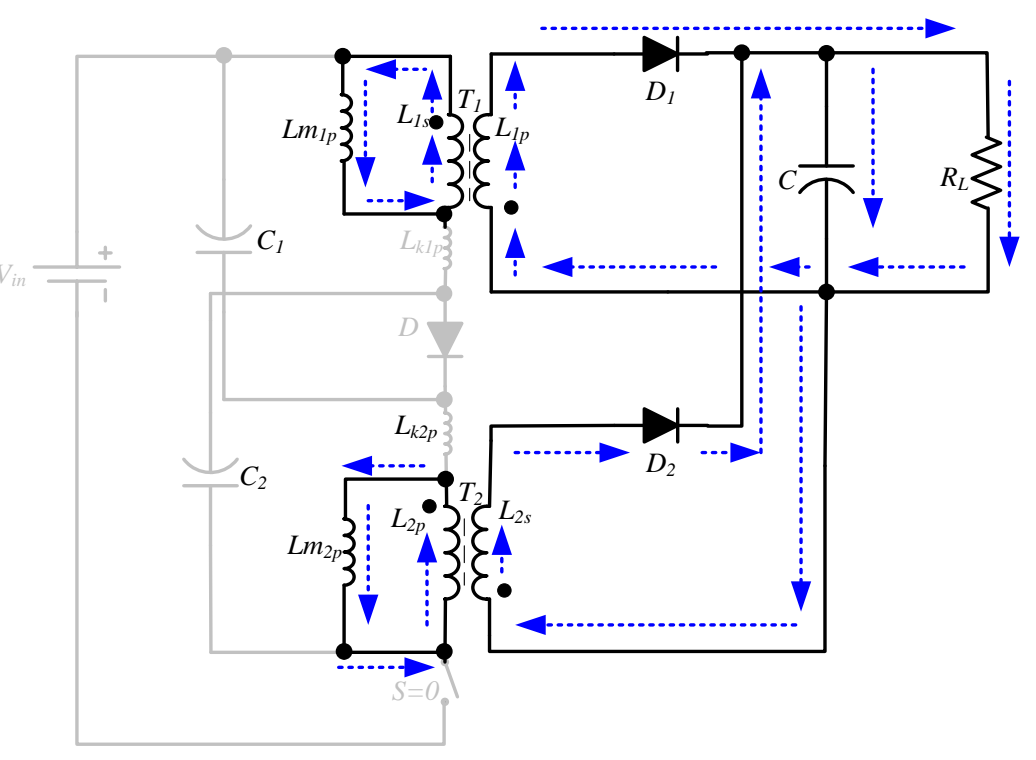

Şekil 8. Dual flyback konvertörün D modunda çalışırken akım yönleri.

\subsection{Fotovoltaik Güneş Pilleri}

Fotovoltaik güneş pilleri, güneş 1şı̆̆ını elektrik enerjisine çeviren yarı iletken bileşenlerdir (Yang, 2018). Fotovoltaik güneş pillerinin davranışını ve elektriksel özelliklerini incelemek için, elektrik devre elemanlarından oluşan eşdeğer bir devreye ihtiyaç vardır (Alfaro ve Vilanova, 2016). Literatürde basit ve gelişmiş fotovoltaik güneş pilleri için farklı eşdeğer devre modelleri bulunmaktadır (Bianchi ve ark., 2006). Fotovoltaik güneş pilleri ideal elementler olmadıkları için fiziksel yapıları gereği kayıp elementlerdir. Bu nedenle kayıplar dirençlerle temsil edilir.

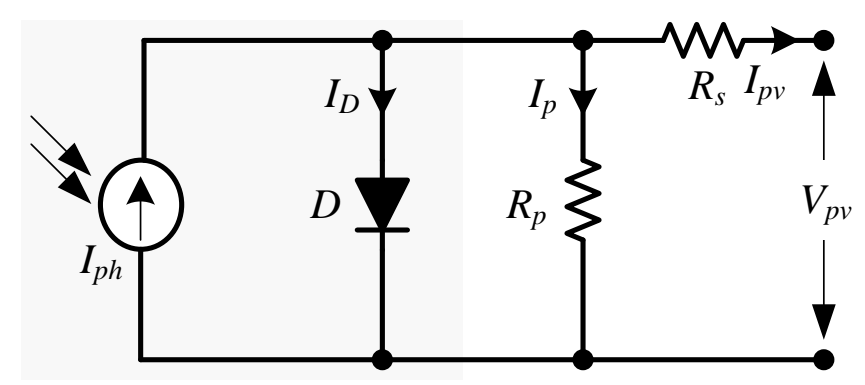

Şekil 9. PV güneş pili eşdeğer devresi.

Bir fotovoltaik güneş pili için yaygın olarak kullanılan eşdeğer devre modeli Şekil 9'da görülmektedir. $\mathrm{I}_{\mathrm{ph}}$ akım kaynağı, fotonlar tarafından üretilen akımı gösterir ve sabit radyasyon ve sıcaklık altında sabittir. Paralel $R_{p}$ direnci, kaçak akımı ve çıkıştaki voltaj düşüşüne karşı seri $R_{s}$ 
direncini temsil etmek için kullanılır. Fotovoltaik bataryadaki dönüşümün verimliliği, $\mathrm{R}_{\mathrm{s}}$ 'deki küçük değişikliklere duyarlıdır. Ancak, $\mathrm{R}_{\mathrm{p}}$ 'deki değişikliklere duyarlı değildir. $\mathrm{R}_{\mathrm{s}}$ 'deki küçük bir artış, fotovoltaik modülün (Damiano ve ark., 1999) çıkışını önemli ölçüde azaltır.

PV hücresinin çıkış voltajı Denklem 25'de verilmiştir (Zenk ve ark., 2011). Burada kullanılan değişkenlerin açıklamaları Tablo 1'de görülmektedir.

$$
V_{P V}=\frac{N}{\lambda} \ln \left(\frac{I_{S C}-I_{P V}+M I_{0}}{M I_{0}}\right)-\frac{N}{M} R_{S} I_{P V}
$$

Tablo 1. PV güneş hücresi ile ilgili temel bilgiler.

\begin{tabular}{ccc}
\hline Sembol & Tanım & Birim \\
\hline$V_{P V}$ & PV hücre çıkış gerilimi & $\mathrm{V}$ \\
$I_{P H}$ & Işınlama seviyesinin ve sıcaklı birleşiminin bir fonsiyonu & $\mathrm{A}$ \\
& olarak Foto akım, & \\
$I_{P V}$ & PV hücre çıkış akımı & $\mathrm{A}$ \\
$I_{S C}$ & Hücre kısa devre akımı & $\mathrm{A}$ \\
$I_{0}$ & Ters satürasyon akımı & $\mathrm{A}$ \\
$R_{S}$ & PV hücrenin seri direnci & $\Omega$ \\
$N$ & Dizi başına hücre sayısı & \\
$\lambda$ & Sabit bir katsayı \\
$M$ & Paralel dizi sayısı & \\
\hline
\end{tabular}

Seçilen güneş paneli bir BP SX3190 modelidir ve piyasadan kolayca temin edilebilir. Tablo 2, silikon nitrür çok kristalli silikon hücreli yüksek verimli fotovoltaik modül ile ilgili bilgileri gösterir.

Tablo 2. Seçilen PV panel teknik bilgileri.

\begin{tabular}{cc}
\hline Birim & Değer \\
\hline Açık devre voltajı & $30,6021 \mathrm{~V}$ \\
Kisa devre akımı & $8,51029 \mathrm{~A}$ \\
Maksimum güç & $190 \mathrm{~W}$ \\
Maksimum güç noktasında voltaj & $24,3003 \mathrm{~V}$ \\
Maksimum güç noktasında akım & $7,82945 \mathrm{~A}$ \\
Kisa devre akımının sıcaklık katsayısı & $(0,065 \pm 0,015) \% /{ }^{\circ} \mathrm{C}$ \\
Açık devre voltajının sıcaklık katsayısı & $-(111 \pm 10) \mathrm{mV} /{ }^{\circ} \mathrm{C}$ \\
Seri direnç & $0,17514 \mathrm{ohm}$ \\
Paralel direnç & $755,51 \mathrm{ohm}$ \\
Diyot doygunluk akımı & $1,0647 \mathrm{e}-6 \mathrm{~A}$ \\
Diyot ideallik faktörü & 1,5 \\
\hline
\end{tabular}




\subsection{Fuzzy-Tuned PI Denetleyici}

Fuzzy-tuned PI denetleyicilerin basitleştirilmiş blok diyagramı Şekil 10'da gösterilmektedir. Bu kontrolör tipi giriş hatası (e), hata değişikliği (de) ve kontrolör çıkışı (du) için üyelik fonksiyonları normalleştirilmiş etki alanında [-1,1] Şekil 11'de gösterildiği gibi tanımlanmıştır. $\beta$ üyelik fonksiyonları (MF) ise [0, 1] aralığında Şekil 12'de gösterildiği gibi tanımlanır.

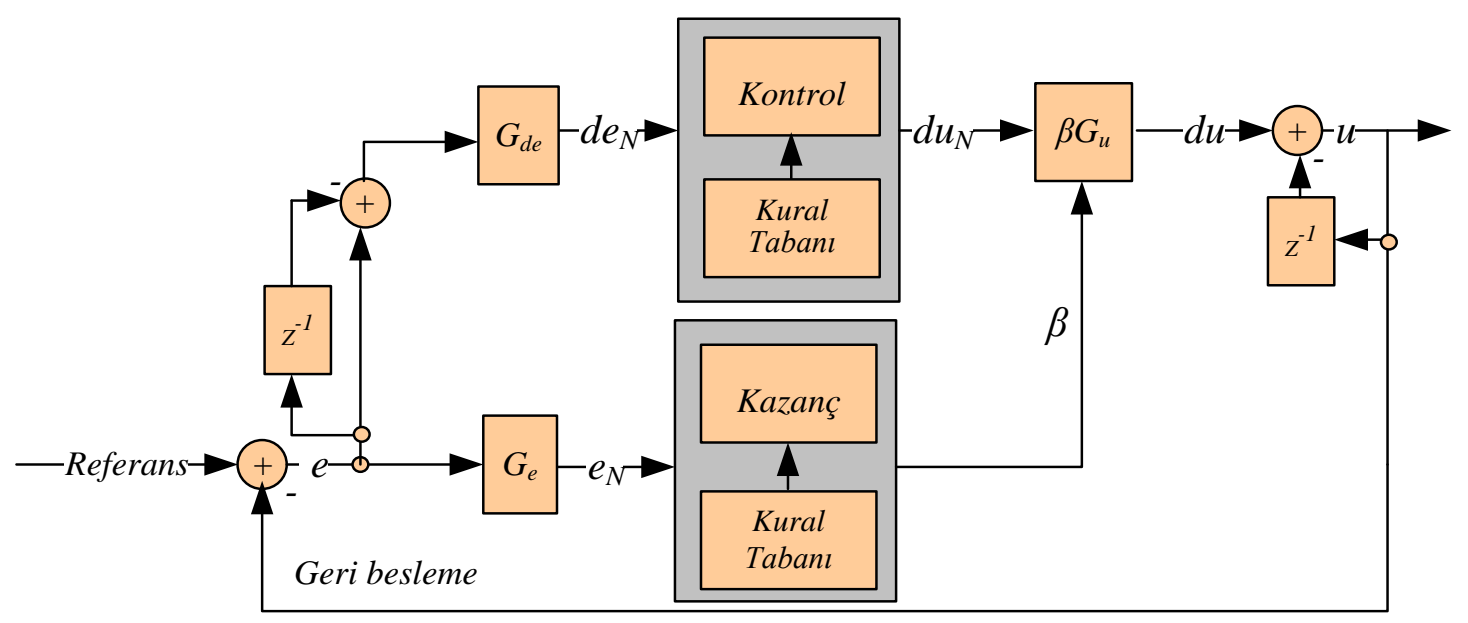

Şekil 10. Fuzzy-tuned PI denetleyicinin temel konfigürasyonu.

Doğal ve tarafsız doğası nedeniyle, eşit taban genişliğine ve komşu MF'lerle \% 50 örtüşmeye sahip simetrik üçgenler burada kullanılır (Pal ve Naskar, 2013). PI tipi FLC için e, de, du terim kümeleri dilsel değerlerin büyüklük kısmı için aynı dilsel ifadeleri içerir (Zenk ve Akpinar, 2013; Zenk, 2016).

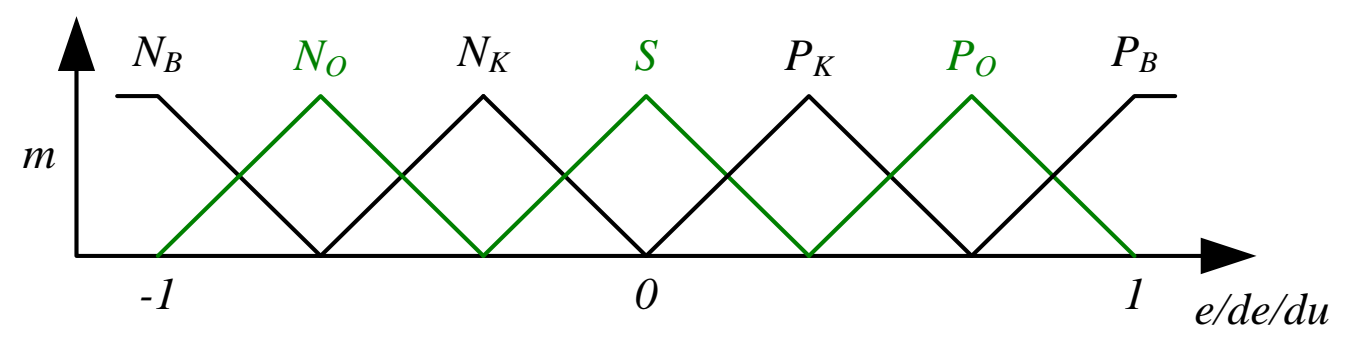

Şekil 11. Üyelik fonksiyonundaki girişler (e, de) ve çıkış (du), $L_{e}=L_{d e}=L_{d u}\left\{N_{B}, N_{O}, N_{K}, S, P_{K}, P_{O}, P_{B}\right\}$. 


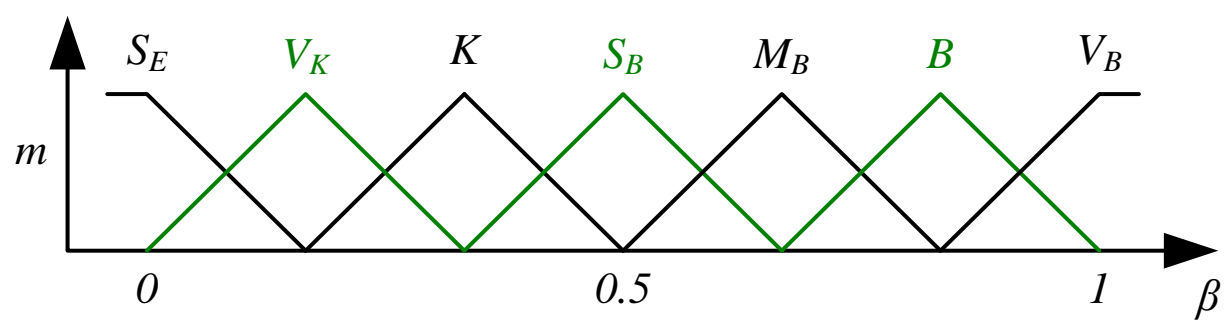

Şekil 12. Kazanç güncelleme faktörü $\beta$ 'nın $M F^{\prime}$ lere eşlenmesi $\left\{S_{E}, V_{K}, K, S_{B}, M_{B}, B, V_{B}\right\}$.

Burada du, kontrolör çıkışındaki artımlı değişikliktir. Fuzzy-tuned PI denetleyici Şekil 10 ve denklem (26)'da gösterildiği gibi basit bulanık PI denetleyicisinin çıkışı değiştirilerek doğrusal olmayan denetleyici çıkışı, (du)'nun üretilmesi sağlanır.

$$
\begin{aligned}
& u(k)=u(k-1)+d u(k) \\
& d u=\beta G u\left(d u_{N} 1\right)
\end{aligned}
$$

\subsection{Fractional PID Denetleyiciler $\left(\mathrm{PI}^{\lambda} \mathrm{D}^{\mu}\right)$}

Fractional tip PID denetleyicileri, PID'lerin genelleştirilmiş formu olarak tanımlanabilir. Başka bir ifade ile sistem çıktı verileri, girdinin doğrusal bir kombinasyonu, girdinin kesirli bir türevi ve girdinin bir kesirli integrali olarak özetlenebilir (Podlubny, 1998). Kesirli PID'ler aynı zamanda PI ${ }^{\lambda}{ }^{\mu}$ denetleyicileri olarak da bilinir; burada $\lambda$ ve $\mu$, entegrasyon ve farklılaşma sıralarıdır; her iki değer de 1 ise, sonuç normal bir PID'dir (bundan böyle kesirli bir PID'nin aksine "tamsayı" PID olarak adlandirilır).

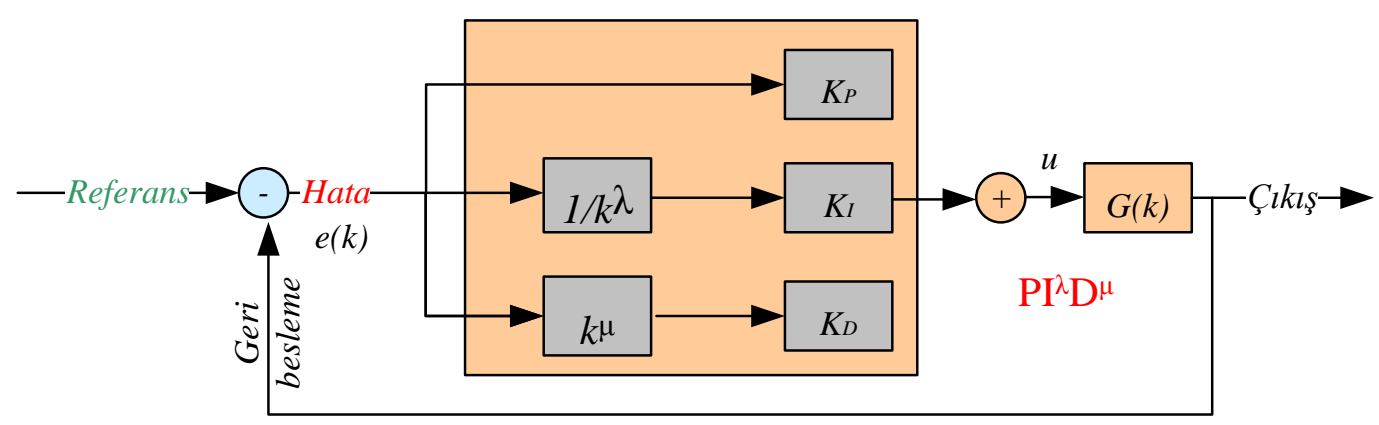

Şekil 13. $\mathrm{PI}^{\lambda} \mathrm{D}^{\mu}$ PID Kontrolörün temel konfigürasyonu. 
$\mathrm{PI}^{\lambda} \mathrm{D}^{\mu}$ denetleyicileri, klasik PI denetleyicilerinden daha iyi sonuçlar verebilen gelişmiş denetleyicilerdir. PID denetleyicilerinden daha hassas ayar yapabildikleri için yaygın olarak kullanılmaktadırlar. En iyi bilinenler M. Caputo, Grunwald-Letkinov ve Reimann-Liouville'in (Shah ve Agashe, 2016; Rasoanarivo ve Sargos, 2013) tanımlarıdır. $\mathrm{PI}^{\lambda} \mathrm{D}^{\mu}$ kontrolör genel blok şeması Şekil 13 'te gösterilmektedir.

Bu çalışmada $\lambda$ ve $\mu \geq 0, \lambda$ entegrasyon sırası ve $\mu$ farklılaştırıcı sıradır. $K_{P}, K_{I}$ ve $K_{D}$, PID denetleyici kazanımlarıdır. U (s) ve E (s) sırasıyla kontrol ve hata sinyalleridir. Bu çalışmada, $\mathrm{PI}^{\lambda} \mathrm{D}^{\mu}$ kontrolör yazılımı FOMCON Toolbox (Tepljakov, 2017) tarafından yapılmıştır. Sistem çıkışı, $C(k)$ Denklem 28'de görüldüğü gibidir.

$$
C(k)=\mathrm{K}_{P}+\frac{K_{I}}{k^{\lambda}}+K_{D} k^{\mu}
$$

\section{Bulgular ve Tartışma}

Tasarlanan sisteme ait Matlab/Simulink dijital ortamında hazırlanan devre Şekil 14'te verilmiştir. Tüm veriler incelenirken ortam sıcaklık değeri $\mathrm{t}=25^{\circ} \mathrm{C}$ olarak alınmış, güneş 1şınım değeri ise değişken bir grafikle belirlenmiştir. Yük olarak $23 \Omega$ ’luk bir sabit yük kullanılmıştır. Ayrıca sistemde kullanılan dual flyback dönüştürücüye bağlı Bulanık ayarlı PI ve kesir dereceli PID kontrolörün katsayı değerleri aynıdır. Kontrol tekniğinde ise kesir dereceli PI'da Caputo yaklaşımı kullanılmıştır. Sistemde anahtarlama frekansı $50 \mathrm{kHz}$ seçilmiştir. Bu bölümde çalışma sonucunda elde edilen bulgular verilmektedir. 


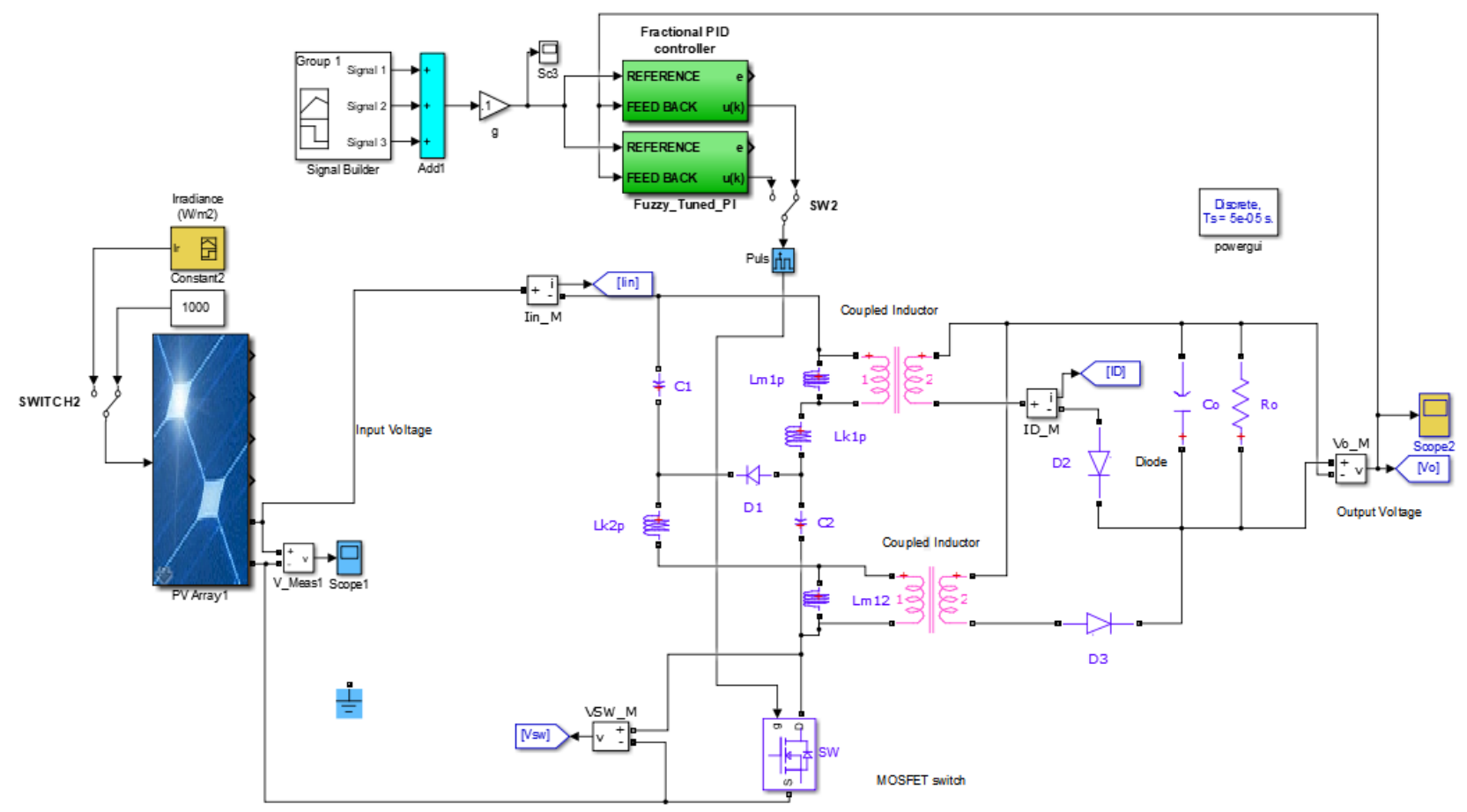

Şekil 14. Tasarlanan sistemin Matlab/Simulink ortamındaki gösterimi.

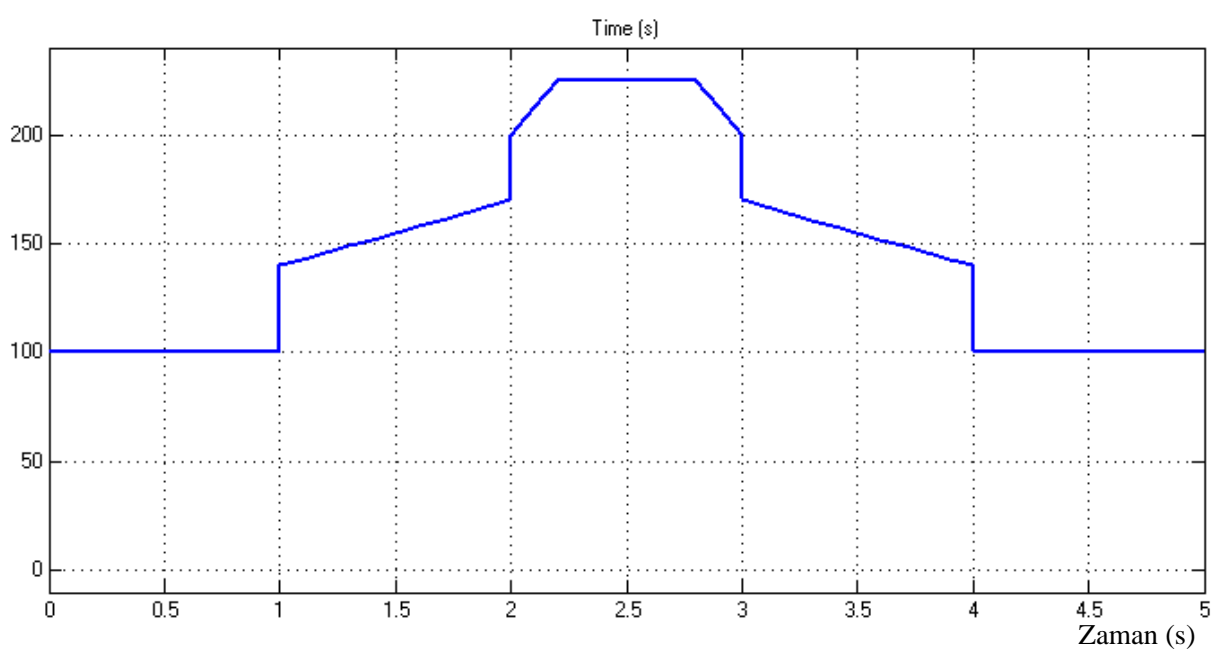

Şekil 15. Tasarlanan sistemdeki çıkış gerilimini sağlaması istenen referans gerilim değerinin zamanla değişimi.

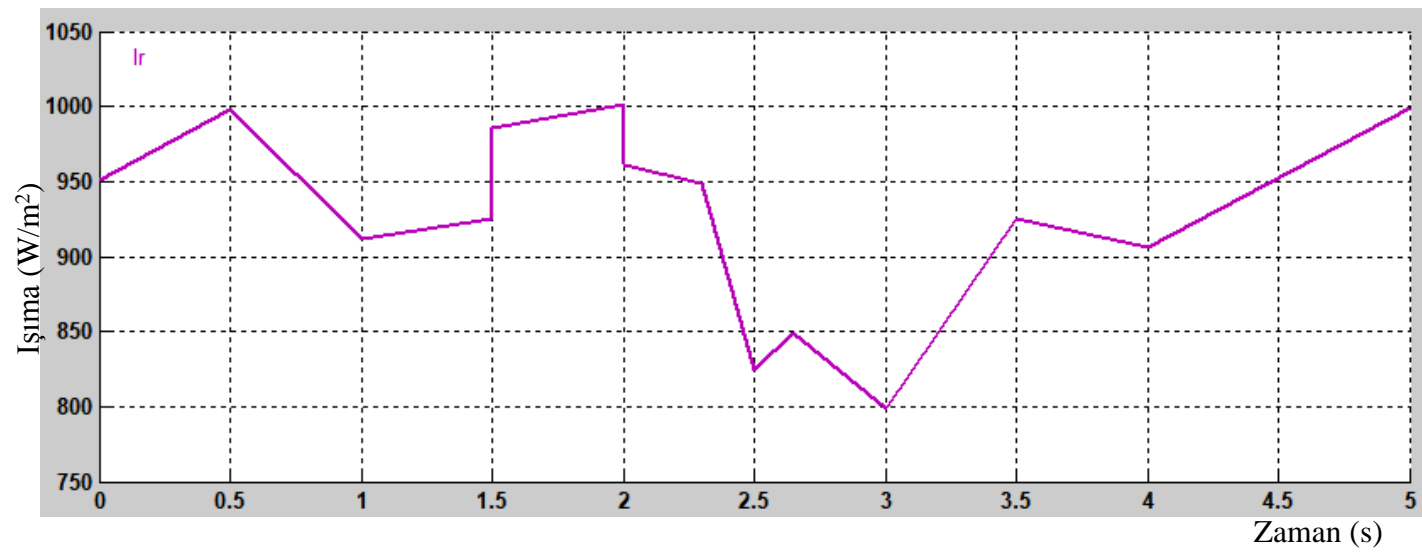

Şekil 16. Zamanla değişen güneş 1şınım durumu 


\subsection{Fuzzy-Tuned PI Kontrollü Sistem Çıktıları}

Şekil 14'te verilen sistemde kontrolör olarak Fractional PID seçildiğinde önerilen dual flyback dönüştürücünün bazı parametrelerinin 5 saniyelik değişimi Şekil 17’de verilmiştir.

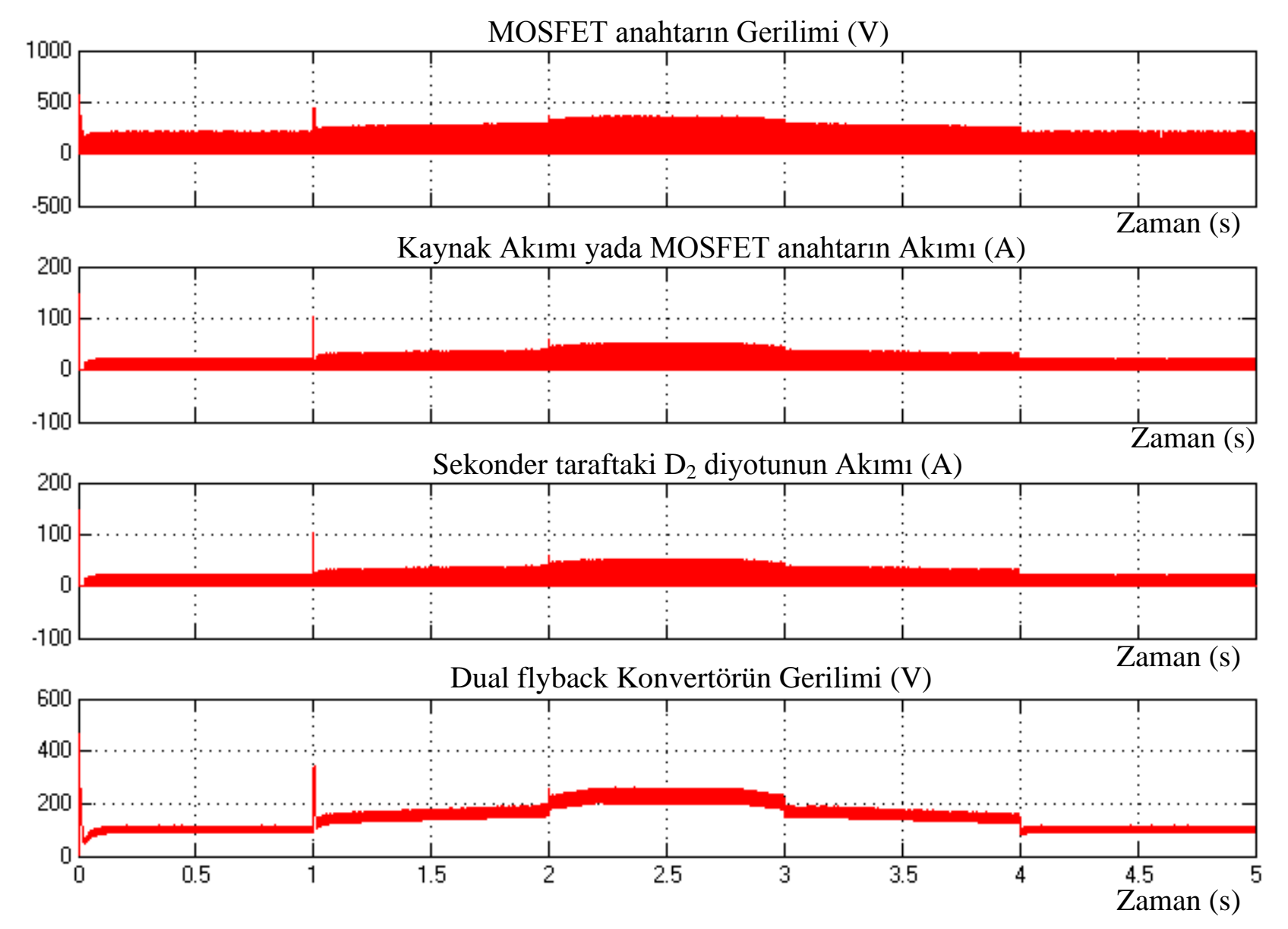

Şekil 17. Fuzzy-tuned PI denetimli Sistem parametreleri

Tablo 3. Fuzzy-tuned PI denetimli sistemin verileri.

\begin{tabular}{cccccc}
\hline Zaman Aralığı (s) & Referans & Çıkıs Gerilimi $(\mathbf{V})$ & $\boldsymbol{\Delta} \mathbf{V}=\mathbf{V}_{\text {ref }}-\mathbf{V}_{\mathbf{0}}$ & \% Hata & Şekil 18 \\
\hline $0-0,01$ & 100 & 469,7 & $-369,7$ & 369,7 & b) \\
0,02 & 100 & $90-115$ & 2,5 & 2,5 & b) \\
$1-1,05$ & $100-140$ & 343,6 & $-203,6$ & 145,42 & c)-d) \\
1,05 & 141,5 & $120-150$ & 6,5 & 4,59 & c) \\
$2-2,01$ & $170-200$ & 260 & 60 & 30 & e)-f) \\
2,02 & 200 & $182-228$ & 5 & 2,5 & f) \\
4,6 & 100 & $90-115$ & 2,5 & 2,5 & g) \\
2,5 & 225 & $202-258$ & 2,5 & 1,11 & h) \\
$1,492-1,504$ & 155 & $138-178$ & -3 & 1,93 & i) \\
0,5 & 100 & $89-112$ & $-1,5$ & 1,5 & j) \\
\hline
\end{tabular}


Tablo 3'te verilen bilgiler incelendiğinde \% hataların toplamı \%561,75 bulunur. Bu hata değeri alınan on adet örneklemeye oranlanırsa yaklaşık bir ortalama değer bulunur. $\mathrm{Bu}$ değer \% 56,178 bulunur.

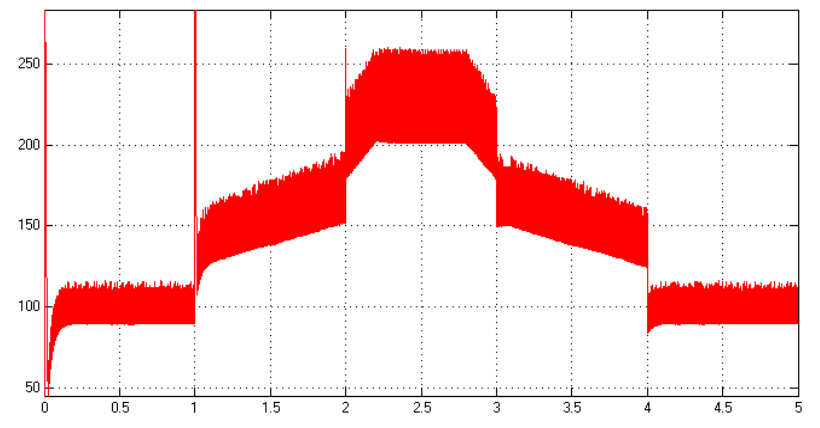

a)

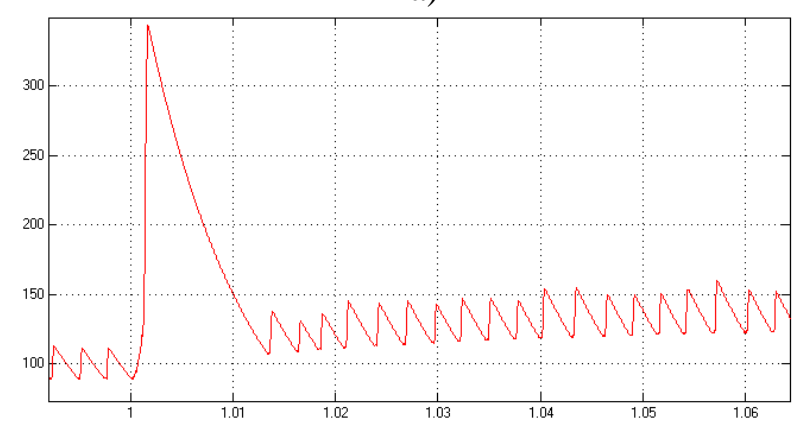

c)

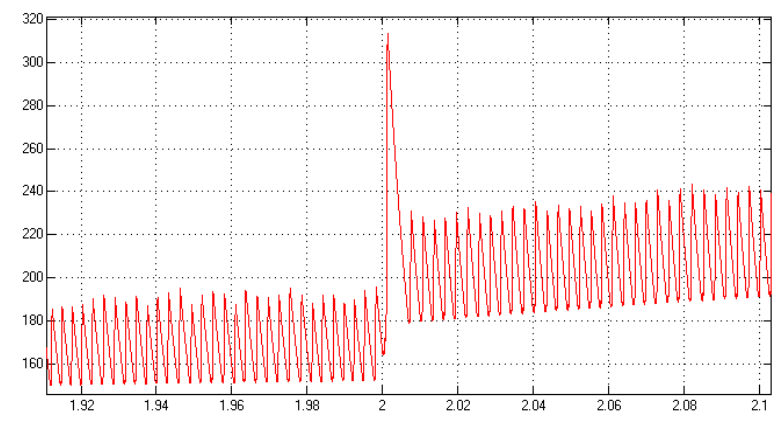

e)

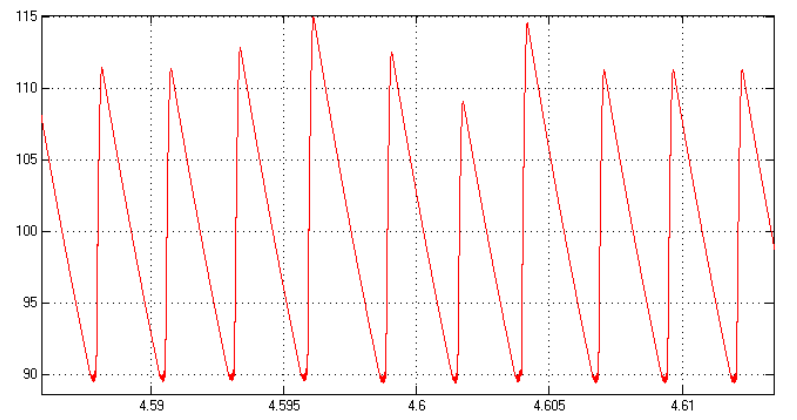

g)

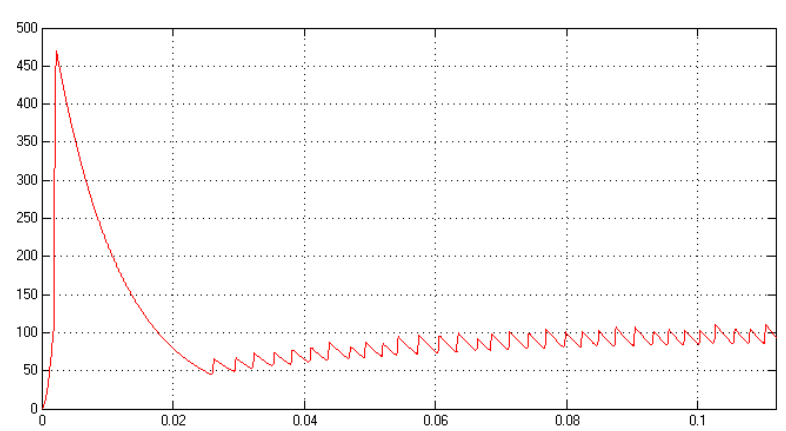

b)

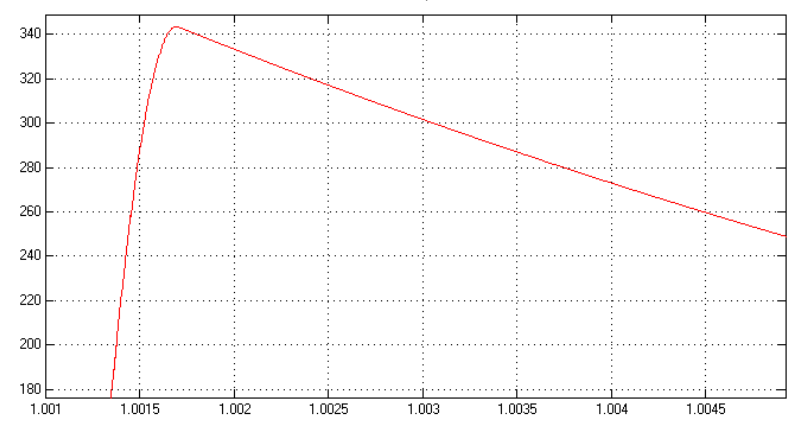

d)

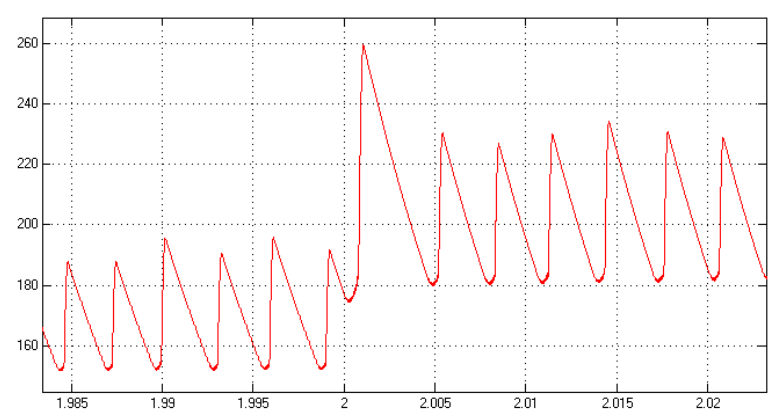

f)

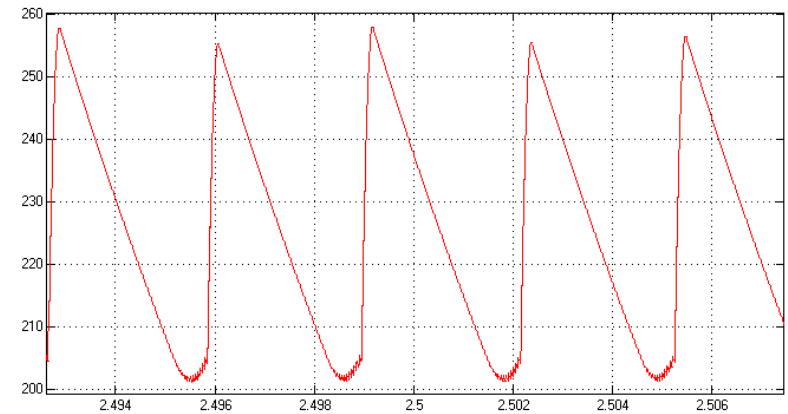

h) 


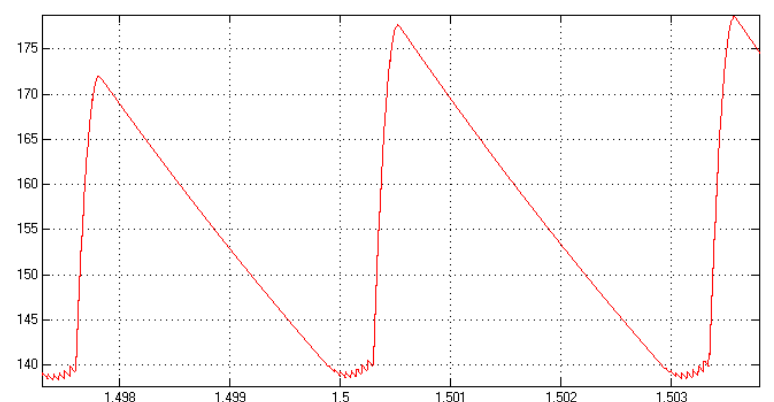

i)

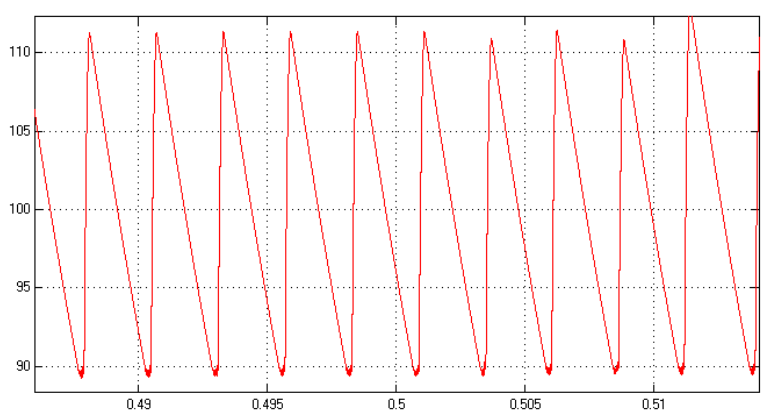

j)

Şekil 18. Fuzzy-tuned PI denetimli dual flyback dönüştürücünün çıkış gerilim (V) - zaman (s) sinyalleri.

\subsection{Fractional PID Kontrollü Sistem Çıktıları}

Şekil 14'te verilen sistemde kontrolör olarak fractional PID seçildiğinde önerilen dual flyback konvertörün bazı parametrelerinin 5 saniyelik değişimi Şekil 19’da verilmiştir.
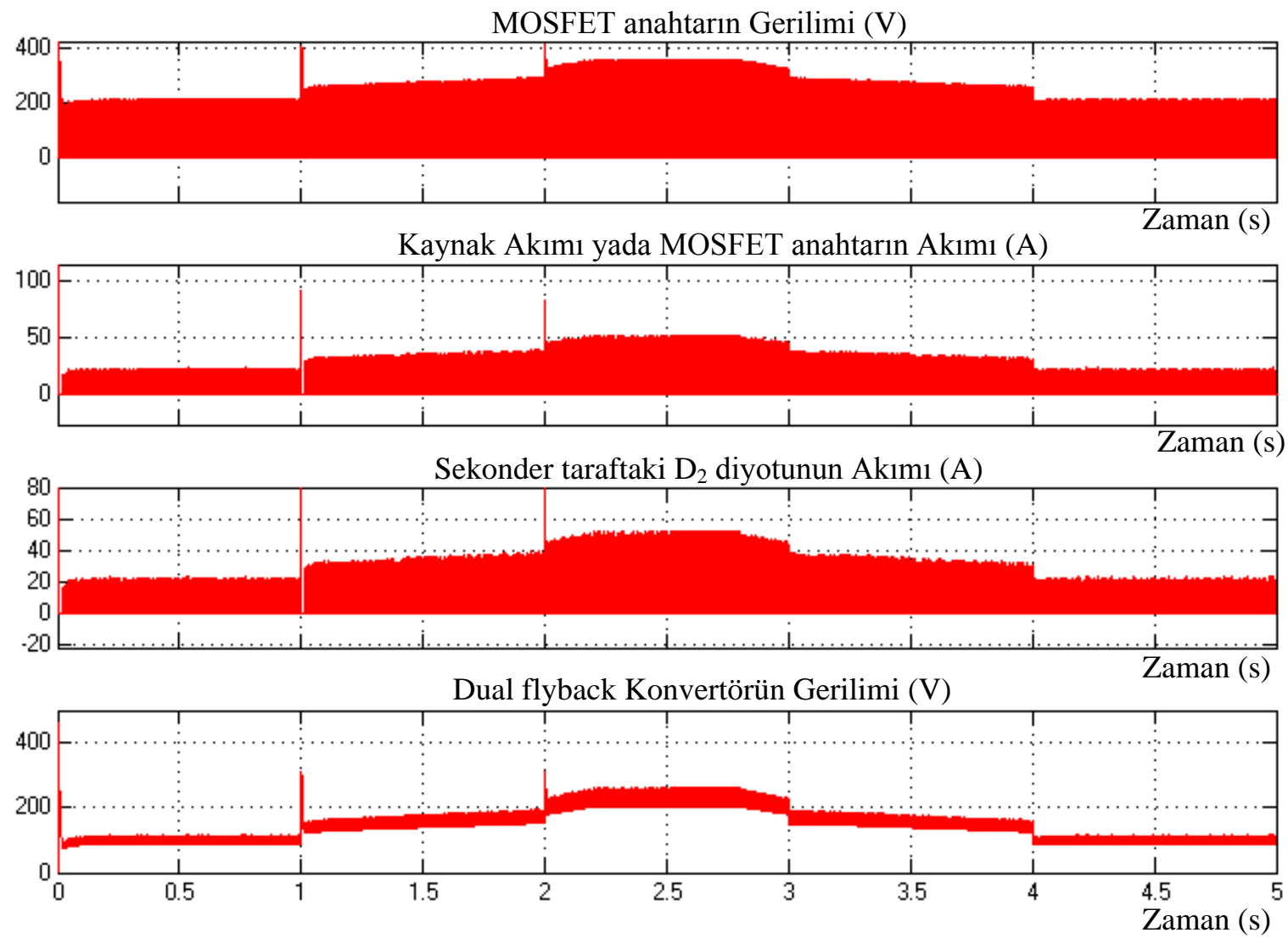

Şekil 19. Fractional PID denetimli sistem parametreleri 
Tablo 4. Fractional PID denetimli sistemin verileri.

\begin{tabular}{cccccc}
\hline Zaman Aralığı (s) & Referans & Çıkıs Gerilimi $(\mathbf{V})$ & $\boldsymbol{\Delta V}=\mathbf{V}_{\text {ref }}-\mathbf{V}_{\mathbf{0}}$ & \% Hata & Şekil 20 \\
\hline $0-0,01$ & 100 & 460 & -360 & -360 & b) \\
0,02 & 100 & 90 & 10 & 10 & b) \\
$1-1,05$ & $100-140$ & 310,5 & $-170,5$ & 82,11 & c)-d) \\
1,05 & 141,5 & 140 & 1,5 & 1,06 & c) \\
$2-2,01$ & $170-200$ & 313,1 & 113,1 & 56,55 & e)-f) \\
2,02 & 200 & $180-200$ & 0 & 0 & f) \\
4,6 & 100 & $90-110$ & 0 & 0 & g) \\
2,5 & 225 & $205-260$ & 7,5 & 3,33 & h) \\
$1,492-1,504$ & 155 & $140-180$ & -5 & $-3,22$ & i) \\
0,5 & 100 & $90-113$ & $-1,5$ & 1,5 & j) \\
\hline
\end{tabular}

Tablo 4'te verilen bilgiler incelendiğinde $\%$ hataların toplamı \%517,77 bulunur. Bu hata değeri alınan on adet örneklemeye oranlanırsa yaklaşık bir ortalama değer bulunur. Bu değer \% 51,777 bulunur.

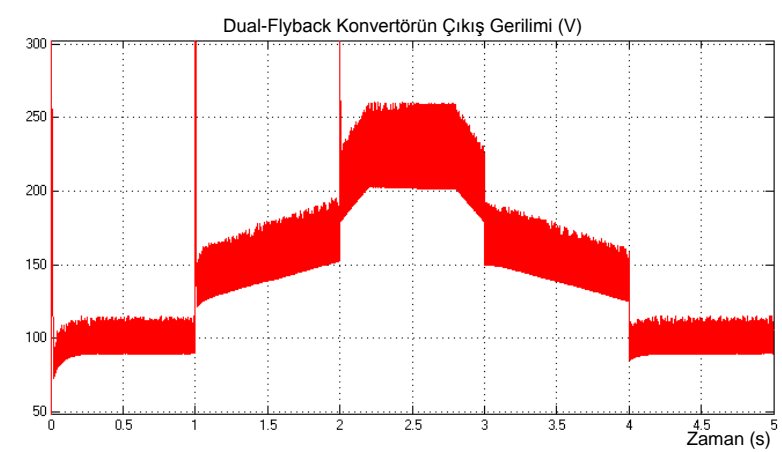

a)

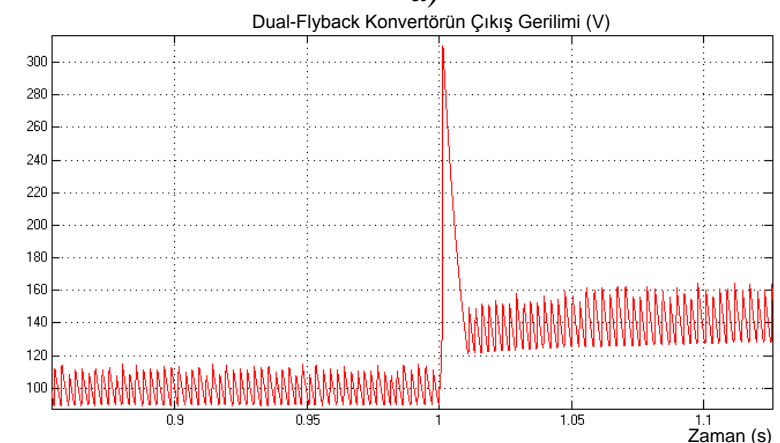

c)

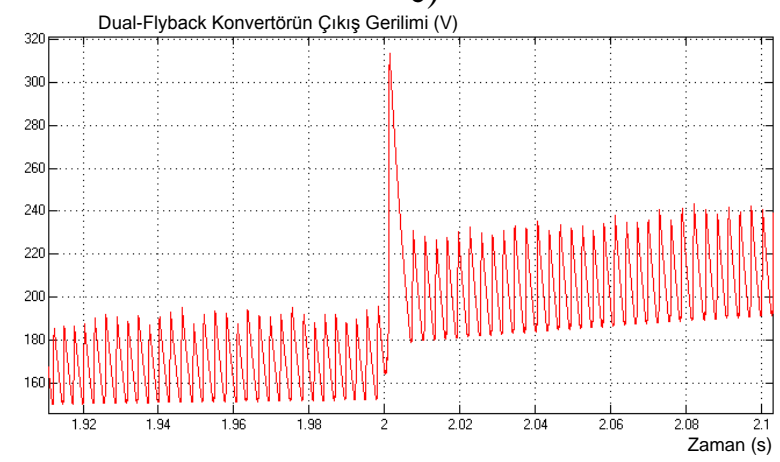

e)

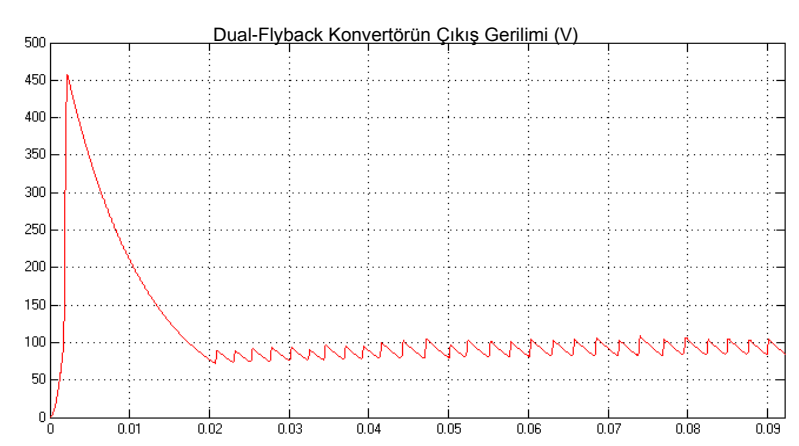

b)

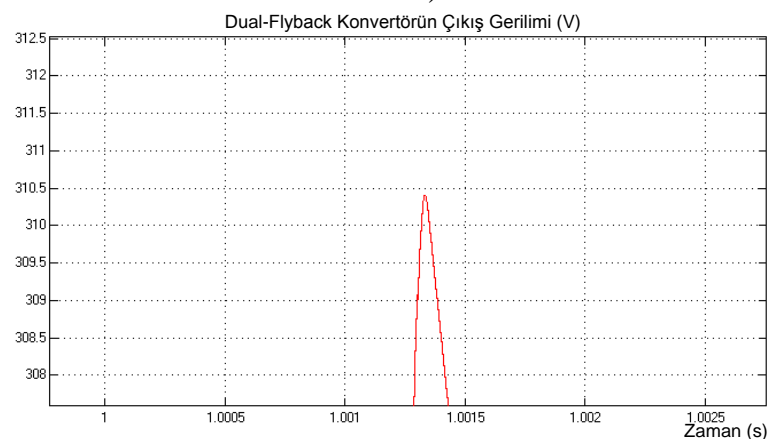

d)

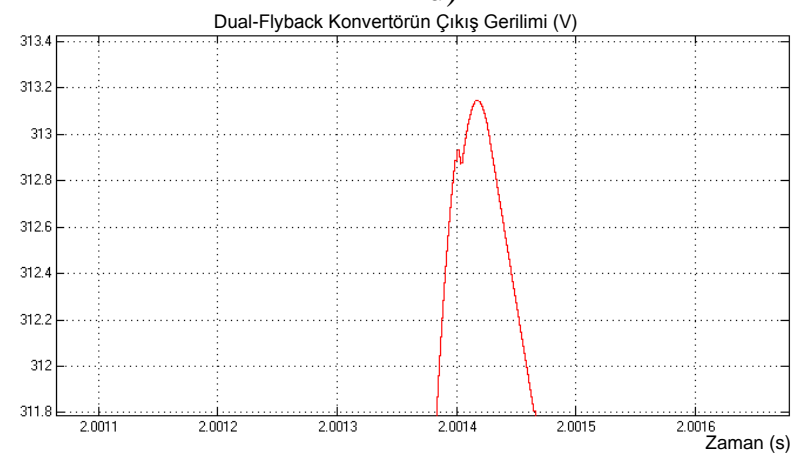

f) 


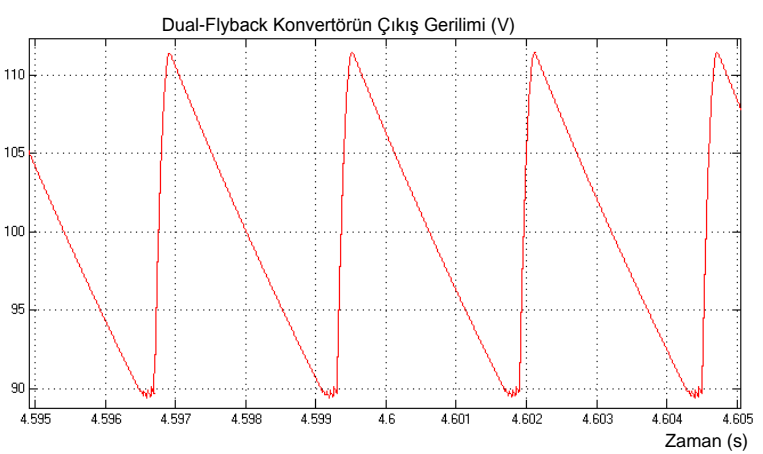

g)

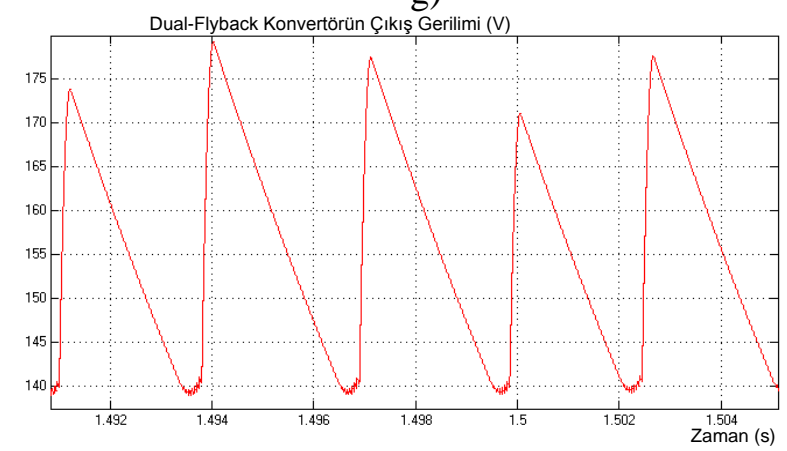

i)

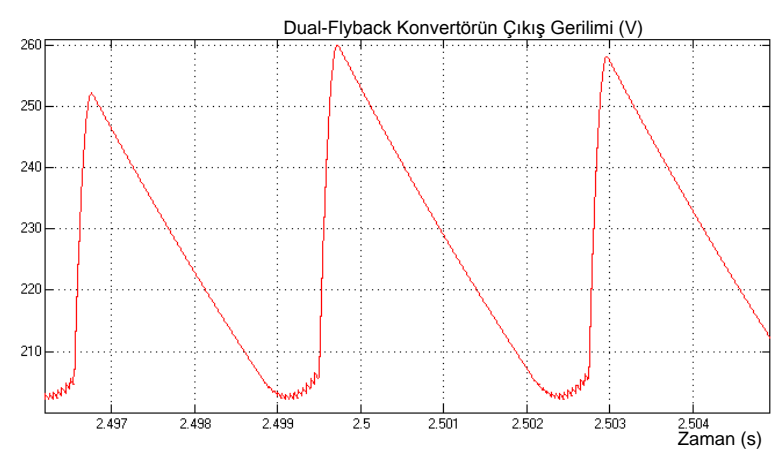

h)

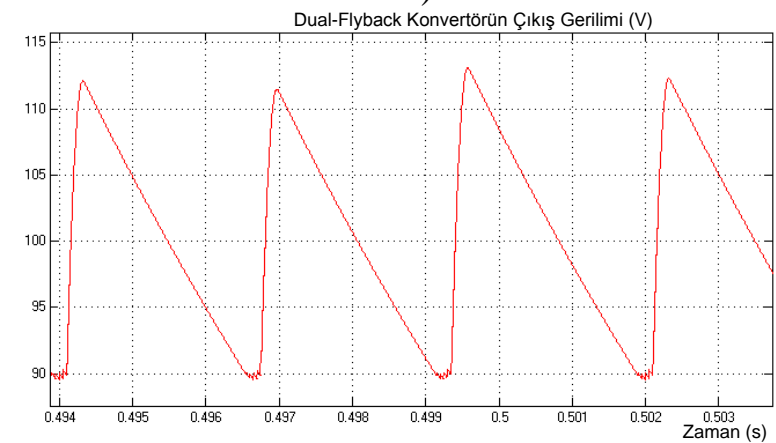

j)

Şekil 20. Fractional PID denetimli dual flyback dönüştürücünün çıkış gerilim (V) - zaman (s) sinyalleri.

\section{Sonuçlar ve Öneriler}

Mevcut klasik DC flyback dönüştürücü, basit yapısı ve düşük maliyeti sebebiyle önemli bir kullanım alanına sahiptir. Bununla birlikte, bu dönüştürücüler aynı zamanda transformatörün kaçak endüktansa da sahiptir. Bu durum daha düşük bir verimlilikle sonuçlanır. Bu çalışmada, önerilen dönüştürücüde yalnızca tek bir anahtar ve aynı endüktansa sahip iki transformatör kullanılmıştır. Anahtarın kapalı periyodu sırasında, transformatörlerin mıknatıslanma endüktansının enerjileri çıkışa aktarılır. Bu arada transformatörlerin kaçak enerjileri geri dönüştürülebilir. Elde edilen deneysel sonuçlardan transformatörlerin kaçak enerjilerinin geri dönüştürüldüğü görülmektedir. Bu yeni konvertör ileri kontrolörlerden fuzzy-tuned PI ve fractional PID kontrolörün uyumlu bir şekilde çalışabildiği gösterilmiştir. Elde edilen sonuçların detaylı olarak verildiği Tablo 3 ve Tablo 4 incelendiğinde, fractional PID denetimindeki dual flyback konvertör sisteminin referans işareti izleme başarısı fuzzy-tuned PI bağlı sistemden daha iyi olduğu görülür. Ayrıca Şekil 18 ve Şekil 20 detaylı olarak incelendiğinde, referans sinyaldeki değişimlere fractional PID denetimli sistem, fuzzytuned PI bağlı sistemden daha hızlı tepki vererek hata payını sıfıra götürüyor.

Ancak, her iki denetleyicinin bağlı olduğu dual flyback dönüştürücü sistemi de referans işareti kabul edilebilir bir sürede kontrol etmeyi başarmıştır. 


\section{Kaynaklar}

Alfaro, V. M., \& Vilanova, R. (2016). Model-reference robust tuning of PID controllers (p. 202). Berlin, Germany: Springer.

Bianchi, N., Bolognani, S., \& Luise, F. (2006). High speed drive using a slotless PM motor. IEEE Transactions on Power Electronics, 21(4), 1083-1090.

Chen, G., Lee, Y. S., Hui, S. Y. R., Xu, D., \& Wang, Y. (2000). Actively clamped bidirectional flyback converter. IEEE Transactions on Industrial Electronics, 47(4), 770-779.

Damiano, A., Gatto, G., Pisano, A., \& Usai, E. (1999, July). Digital second order sliding mode control of PM DC motor. In ISIE'99. Proceedings of the IEEE International Symposium on Industrial Electronics (Cat. No. 99TH8465) (Vol. 1, pp. 322-326). IEEE.

Fathima, M. B., Princy, P. M. J., \& RamPrasath, S. (2017, April). Mathematical modeling of SVPWM inverter fed 3 phase induction motor vector control in MATLAB/Simulink environment. In 2017 International Conference on Circuit, Power and Computing Technologies (ICCPCT) (pp. 1-8). IEEE.

Finney, S. J., Williams, B. W., \& Green, A. T. C. (1996). RCD snubber revisited. IEEE Transactions on Industry Applications, 32(1), 155-160.

Guner, F., \& Zenk, H. (2020). Experimental, Numerical and Application Analysis of Hydrokinetic Turbine Performance with Fixed Rotating Blades. Energies, 13(3), 766.

Kim, M. G., \& Jung, Y. S. (2009). A novel soft-switching two-switch flyback converter with a wide operating range and regenerative clamping. Journal of Power Electronics, 9(5), 772-780.

Kiyak, E., \& Gol, G. (2016). A comparison of fuzzy logic and PID controller for a single-axis solar tracking system. Renewables: Wind, Water, and Solar, 3(1), 7.

Lee, T. D., \& Ebong, A. U. (2017). A review of thin film solar cell technologies and challenges. Renewable and Sustainable Energy Reviews, 70, 1286-1297.

Murthy-Bellur, D., \& Kazimierczuk, M. K. (2011). Zero-current-transition two-switch flyback pulse-width modulated DC-DC converter. IET power electronics, 4(3), 288-295.

Pal, A. K., \& Naskar, I. (2013). Design of self-tuning fuzzy PI controller in LabVIEW for control of a real time process. International Journal of Electronics and Computer Science Engineering, 2(2), 538-545.

Podlubny, I. (1998). Fractional differential equations: an introduction to fractional derivatives, fractional differential equations, to methods of their solution and some of their applications. Elsevier.

Praveen, J., \& VijayaRamaraju, V. (2017). Materials for optimizing efficiencies of solar photovoltaic panels. Materials Today: Proceedings, 4(4), 5233-5238.

Qian, S., Ye, Y., Wu, H., \& Zhuang, Z. (2016, August). Optimizing PWM switching sequence of inverters using an immune genetic algorithm. In 2016 8th International Conference on Intelligent HumanMachine Systems and Cybernetics (IHMSC) (Vol. 1, pp. 7-10). IEEE.

Rasoanarivo, I., Arab-Tehrani, K., \& Sargos, F. M. (2011, October). Fractional order PID and modulated hysteresis for high performance current control in multilevel inverters. In 2011 IEEE Industry Applications Society Annual Meeting (pp. 1-7). IEEE.

Rasoanarivo, I., \& Sargos, F. M. (2013, October). Multi-objective analysis for designing and controlling microgrids under multi-control with PID, MHCC and FOPID controllers. In 2013 IEEE Industry Applications Society Annual Meeting (pp. 1-8). IEEE.

Saygin, A., \& Kerem, A. (2017, September). Fuzzy logic based control of a loaded asynchronous motor using a 6-switched 3-level inverter. In 2017 18th International Conference on Computational Problems of Electrical Engineering (CPEE) (pp. 1-4). IEEE.

Shah, P., \& Agashe, S. (2016). Review of fractional PID controller. Mechatronics, 38, 29-41.

Soliman, H., Abdelsalam, I., Wang, H., \& Blaabjerg, F. (2017, June). Artificial neural network based DC-link capacitance estimation in a diode-bridge front-end inverter system. In 2017 IEEE 3rd International Future Energy Electronics Conference and ECCE Asia (IFEEC 2017-ECCE Asia) (pp. 196-201). IEEE.

Spiazzi, G., Mattavelli, P., \& Costabeber, A. (2011). High step-up ratio flyback converter with active clamp and voltage multiplier. IEEE Transactions on Power Electronics, 26(11), 3205-3214.

Su, J., \& Sun, D. (2017, August). Model predictive torque-vector control for four-switch three-phase inverterfed PMSM with capacitor voltage offset suppression. In 2017 20th International Conference on Electrical Machines and Systems (ICEMS) (pp. 1-5). IEEE.

Şenol, H., \& Zenk, H. (2020). Determination of the biogas potential in cities with hazelnut production and examination of potential energy savings in Turkey. Fuel, 270, 117577. 
Tepljakov, A. (2017). FOMCON: fractional-order modeling and control toolbox. In Fractional-order Modeling and Control of Dynamic Systems (pp. 107-129). Springer, Cham.

Yang, L. S. (2018). Novel dual DC-DC flyback converter with leakage-energy recycling. Journal of Power Electronics, 18(4), 1007-1014.

Zenk, H., Zenk, O., \& Akpinar, A. S. (2011). Two different power control system load-frequency analysis using fuzzy logic controller. In 2011 International Symposium on Innovations in Intelligent Systems and Applications (pp. 465-469). IEEE.

Zenk, H., \& Akpinar, A. S. (2013). PI, PID and fuzzy logic controlled SSSC connected to a power transmission line, voltage control performance comparison. In 4th International Conference on Power Engineering, Energy and Electrical Drives (pp. 1493-1497). IEEE.

Zenk, H. (2016). A Comparative Application of Performance of the SEPIC Converter Using PI, PID and Fuzzy Logic Controllers for PMDC Motor Speed Analysis. Journal of Multidisciplinary Engineering Science Studies (JMESS), 2(12), 1226-1231.

Zenk, H. (2018a). Investigation of Energy Efficiency in Turkey. Annals of the Faculty of Engineering Hunedoara, 16(1), 93-96.

Zenk, H. (2018b). Low Cost Provides of the Energy Needs of Plateau Houses by Using Photovoltaic Systems. Turkish Journal of Agriculture-Food Science and Technology, 6(12), 1768-1774.

Zenk, H. (2018c). Comparison of Electrical Performances of Power Electronics Switches and an Effective Switch Selection Algorithm. Acta Physica Polonica A, 133(4), 897-901.

Zenk, H. (2019a). Comparison of the Performance of Photovoltaic Power Generation-Consumption System with Push-Pull Converter under the Effect of Five Different Types of Controllers. International Journal of Photoenergy, 2019.

Zenk, H. (2019b). Bulanık Ayarl1-PI denetleyicili Zeta Konvertörün Sürdüğ̈̈, Seri DC Motorunun Kalkınma Akımının Etkili Denetimi. Karadeniz Fen Bilimleri Dergisi, 9(1), 196-211.

Zenk, H., Şenol, H., \& Güner, F. (2019). Lunar Excursion Module Landing Control System Design with P, PI and PID Controllers. Karadeniz Fen Bilimleri Dergisi, 9(2), 390-405. 